\title{
An Extended Age-Hardening Model for Al-Mg-Si Alloys Incorporating the Room-Temperature Storage and Cold Deformation Process Stages
}

\author{
OLE RUNAR MYHR, ØYSTEIN GRONG, and CARMEN SCHÄFER
}

In this article, a new age-hardening model for $\mathrm{Al}-\mathrm{Mg}-\mathrm{Si}$ alloys is presented (named $\mathrm{NaMo-Version} \mathrm{2),} \mathrm{which} \mathrm{takes} \mathrm{into} \mathrm{account} \mathrm{the} \mathrm{combined} \mathrm{effect} \mathrm{of} \mathrm{cold} \mathrm{deformation} \mathrm{and}$ prolonged room-temperature storage on the subsequent response to artificial aging. As a starting point, the original physical framework of NaMo-Version 1 is revived and used as a basis for the extension. This is permissible, since a more in-depth analysis of the underlying particle-dislocation interactions confirms previous expectations that the simplifying assumption of spherical precipitates is not crucial for the final outcome of the calculations, provided that the yield strength model is calibrated against experimental data. At the same time, the implementation of the Kampmann-Wagner formalism means that the different microstructure models can be linked together in a manner that enforces solute partitioning and competition between the different hardening phases which form during aging (e.g., clusters, $\beta^{\prime \prime}$ and $\left.\beta^{\prime}\right)$. In a calibrated form, NaMo-Version 2 exhibits a high degree of predictive power, as documented by comparison with experiments, using both dedicated nanostructure and yield strength data as a basis for the validation. Hence, the model is deemed to be well-suited for simulation of thermomechanical processing of $\mathrm{Al}-\mathrm{Mg}$-Si alloys involving cold-working operations like sheet forming and stretch bending in combination with heat treatment and welding.

DOI: $10.1007 / \mathrm{s} 11661-015-3175-\mathrm{y}$

(C) The Author(s) 2015. This article is published with open access at Springerlink.com

\section{INTRODUCTION}

THE age-hardening Al-Mg-Si alloys achieve their unique mechanical properties through a delicate balance of precipitation hardening, solid solution hardening, and strain hardening. ${ }^{[-3]}$ Because the former strength contribution is by far the most important one, the precipitation sequence and resulting strength evolution occurring during natural and artificial aging of the alloys have been extensively investigated and reported upon in the scientific literature. ${ }^{[4-6]}$ In addition, the chemical composition and atomic structure of the clusters and hardening precipitate which form have been studied in detail by means of various high-resolution experimental techniques along with atomistic modeling. ${ }^{[7-10]}$ Obviously, some of these works must be said

OLE RUNAR MYHR, Adjunct Professor, is with Hydro Aluminium, Research and Technology Development, 6601 Sunndaosøra, Norway, and also with the SFI CASA - Centre for Research-Based Innovation at the Norwegian University of Science and Technology, 7491 Trondheim, Norway. Contact e-mail: ole.runar.myhr@hydro.com ØYSTEIN GRONG, Professor, is with the Department of Materials Science and Engineering, Norwegian University of Science and Technology, 7491 Trondheim, Norway, and also with SFI MANUFACTURING Centre for Research-Based Innovation at SINTEF Raufoss Manufacturing \& the Norwegian University of Science and Technology, 2830 Raufoss, Norway. CARMEN SCHÄFER, Research Scientist, formerly with Hydro Aluminium Rolled Products $\mathrm{GmbH}$, Research and Development Bonn, 53104 Bonn, Germany, is now with Ceratizit Austria GmbH, 6600 Reutte, Austria.

Manuscript submitted on February 19, 2015.

Article published online October 1, 2015 to be at the leading edge of international materials research, which gives aluminum a competitive advantages compared to other structural and functional materials that are not so thoroughly examined.

The complex structural changes that the age-hardening $\mathrm{Al}-\mathrm{Mg}-\mathrm{Si}$ alloys undergo during thermal processing will, in turn, bring about corresponding changes in the mechanical properties at room temperature (RT). ${ }^{[11-19]}$ In the past, the relevant structure-property relationships have been captured mathematically in the combined precipitation, yield strength (YS), and work-hardening (WH) model being developed by two of the authors. ${ }^{[20-22]}$ Later, it has been renamed the nanostructure model (NaMo) in order to reach out to a wider audience and make the work accessible to people with a background in finite element simulations and advanced structural analyses as well. ${ }^{[23-27]}$ Referring to Figure 1, $\mathrm{NaMo}-V e r s i o n ~ 1$ divides the age-hardening process into two main stages, i.e., the solution heat treatment (SHT) stage and the artificial aging (AA) stage, based on a simplified description of the artificial aging reaction sequence. ${ }^{[20-22]}$ At the same time, the important alloy composition dependence of the artificial aging reactions is accounted for through the use of a separate thermodynamic (TD) model, which provides quantitative information about the thermal stability of the different stable and metastable precipitates involved. Furthermore, if NaMo is used in combination with a numerical thermal (TH) model like, for example, WeldSim, the subsequent response of the alloys to welding (W) and post-weld heat treatment (PWHT) can be 


\section{NaMo - Version 1}

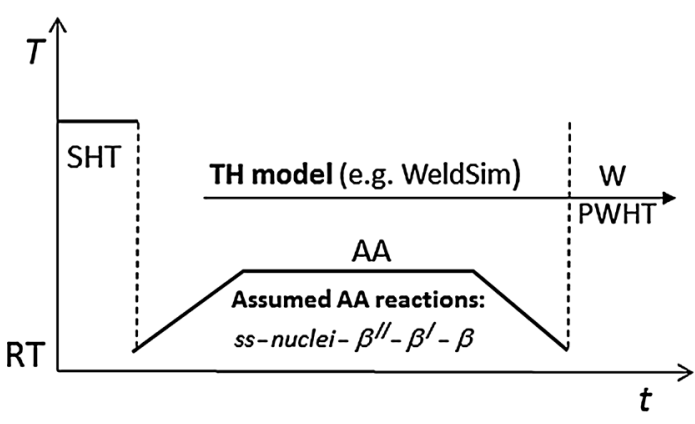

(a)

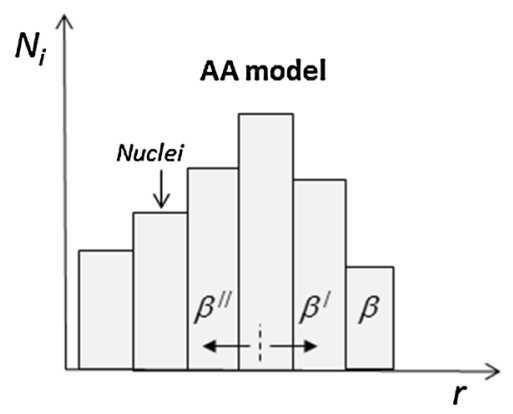

(c)

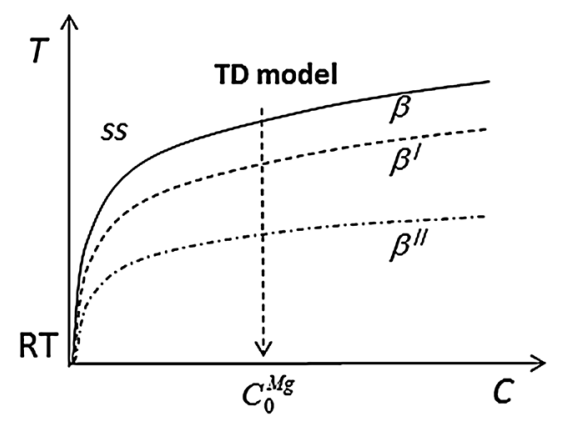

(b)

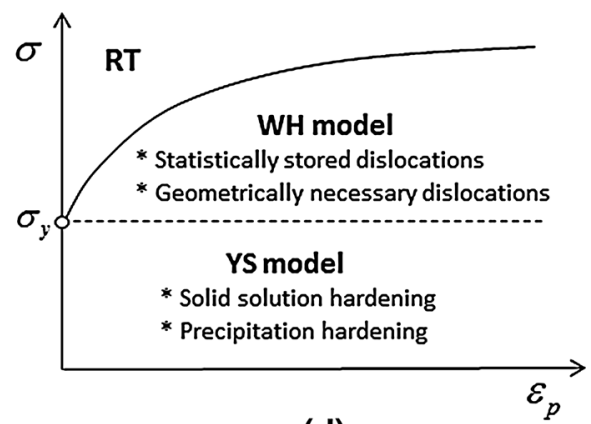

(d)

Fig. 1-Schematic outline of NaMo-Version 1. The abbreviations used in the figure are explained in Appendix A.

simulated. ${ }^{[22,28,29]}$ This is because the memory of a past process step already is captured in the particle size distribution (PSD) being embedded in the artificial aging model. Finally, by employing outputs from the artificial aging model as inputs to the integrated yield strength and work-hardening models, the full stress-strain curve at RT can be calculated for different thermal treatments and alloy compositions and used in more advanced numerical analyses of the mechanical integrity of real aluminum structures. ${ }^{[22,27,29,30]}$

However, problems arise when $\mathrm{NaMo}$ is used in simulations of manufacturing processes involving cold deformation (CD) during a period of prolonged roomtemperature storage prior to artificial aging. This type of thermomechanical processing is not dealt with in Version 1, although cold deformation operations like sheet forming and stretch bending in combination with prolonged room-temperature storage are known to strongly alter the subsequent artificial aging response of Al-Mg-Si alloys. ${ }^{[31-33]}$ Therefore, incorporation of these two new stages in NaMo will largely increase the versatility of the model by allowing simulations of integrated production processes as well of the kind shown in Figure 2. To enable this, the important reactions contributing to the nanostructure evolution at each stage must first be identified (based on what is already known in the scientific literature) and then implemented, either in the existing NaMo sub-models, or in new ones. For example, in NaMo-Version 2, the cluster formation occurring during prolonged room-temperature storage is handled by a new natural aging (NA) model that is linked to the extended

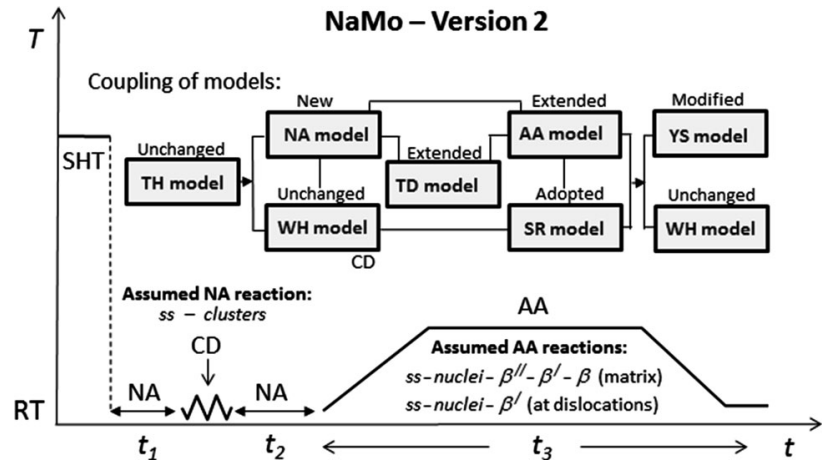

Fig. 2-Schematic outline of NaMo-Version 2. The abbreviations used in the figure are explained in Appendix A.

thermodynamic model for the phase stability in Figure 2. At the same time, dislocation generation caused by cold deformation is captured by the original work-hardening model. When this model is coupled to the static recovery (SR) model (adopted from Nes et al. $\left.{ }^{[34-36]}\right)$ and further to the extended artificial aging model in Figure 2, nucleation and growth of $\beta^{\prime}$ particles at dislocations can be allowed for in the simulations as well. At any time during the artificial aging process, the resulting stress-strain curve at RT can be calculated from the integrated yield strength and work-hardening models for different thermomechanical treatments and alloy compositions and used in more advanced numerical analyses of the mechanical integrity of real aluminum structures. ${ }^{[22-27,29,30]}$ 
In the following, both the new and the adapted models being implemented in NaMo-Version 2 will be described more in detail. Then the experimental program, which has been designed to generate data for calibration and validation of the same models, is outlined. Finally, the applicability of NaMo-Version 2 in illuminating the interplay between the different process variables involved will be illustrated in a dedicated case study.

\section{OUTLINE OF NAMO-VERSION 2}

The abbreviations, symbols, and units used throughout the article are defined in Appendix A.

It is appropriate to start with cluster formation in Al-Mg-Si alloys and the modeling framework, since the natural aging model is the only new one and therefore must be formulated in a way which makes it suitable for direct implementation in NaMo-Version 2.

\section{A. Framework for Modeling Cluster Formation}

Aspects of cluster formation in Al-Mg-Si alloys during natural aging and the subsequent response to artificial aging have been extensively investigated and reported upon in the scientific literature. ${ }^{[31-33,37,38]}$

\section{Problem description}

With a few exceptions, there seems to be general agreement that prolonged storage at $\mathrm{RT}$ and up to about $343 \mathrm{~K}\left(70{ }^{\circ} \mathrm{C}\right)$ will reduce the yield strength of the alloys following artificial aging. ${ }^{[37,38]}$ This is because the clusters, which initially form at low temperatures, tend to survive for a certain period of time during artificial aging and therefore temporarily tie-up solute that otherwise would have been consumed in $\beta^{\prime \prime}$ formation. ${ }^{[11,31-33]}$ At higher storage temperatures, the situation is the opposite due to GP zone formation, since GP zones may convert directly into strengthening $\beta^{\prime \prime}$ particles on subsequent artificial aging. ${ }^{[37,38]}$ However, this type of aging response is not an issue here.

Also detailed characterization of the different types of clusters which form in $\mathrm{Al}-\mathrm{Mg}-\mathrm{Si}$ alloys during natural aging has been carried out using 3D atom probe analyses. ${ }^{[37,38]}$ Still, their exact chemical composition and size distribution are not fully unveiled. This is because many of them contain varying amounts of the constituent atoms $\mathrm{Si}, \mathrm{Mg}$, and $\mathrm{Al}$ inside the core, which makes the interface rather diffuse and the individual clusters hard to uncover. ${ }^{[37,38]}$ Nevertheless, based on a simple mass balance, using reasonable input values for the mean radius (e.g., $\overline{r_{1}}=7 \AA$ ), the number density (e.g., $N_{\mathrm{v}}=10^{24}$ clusters per $\mathrm{m}^{3}$ ), and the pure co-cluster composition (e.g., $\mathrm{Mg}: \mathrm{Si} \approx 1: 1)$, it is easy to verify that a considerable fraction of the solute must be tied-up in the clusters at the end of the natural aging process.

Provided that solute depletion is the actual cause of the RT storage problem, the real modeling challenge is to formulate a natural aging model that describes the evolution of clusters with time under different cold deformation conditions. At the same time, the mathematical description must be sufficiently relevant and comprehensive to promote free exchange of the solute between the different precipitates shown in Figure 2 during subsequent artificial aging when reversion of the clusters occurs.

\section{Modeling strategy}

From the literature reviewed, it is obvious that the kinetics of cluster formation is actually an atomic scale process involving complex interactions between solute atoms and vacancies which cannot readily be accounted for in a simple mathematical treatment of the process. ${ }^{[39,40]}$ Therefore, atomistic modeling is most commonly employed to capture the cluster evolution, ${ }^{[40,41]}$ although simpler models based on the KampmannWagner formalism and the Johnson-Mehl-AvramiKolmogorov (JMAK) equation also exist. ${ }^{[31,42,43]}$ Note that the latter two approaches assume that the cluster formation can be treated as a classic nucleation and growth process, which clearly is an oversimplification of the problem. Still, a natural aging model based on the Kampmann-Wagner formalism is deemed to be the best choice in the present context, since such a model would be fully compatible with the other NaMo models and therefore easy to implement into the existing mathematical framework.

\section{Constitutive laws and equations embedded in the} numerical code

Because of the opportunities that the KampmannWagner formalism provides in terms of modeling flexibility, ${ }^{[4,45]}$ two separate particle size distributions are used in NaMo-Version 2, one to capture the cluster evolution during natural aging and the other one to describe the $\beta^{\prime \prime}$ and $\beta^{\prime}$ formation during artificial aging. Hence, the natural aging and artificial aging models contain separate nucleation and rate laws and input data but are linked together via the continuity equation which keeps a record of the amount of solute being tied-up as precipitates. ${ }^{[20,44,45]}$ This allows the mean solute concentration in the aluminum matrix $\bar{C}$ to be computed and shared among the two populations of precipitates. The equilibrium magnesium concentration at the particle/matrix interface $C_{\mathrm{e}}^{\mathrm{Mg}}$ is, in turn, calculated via the extended thermodynamic model, which is based on a simplified quasi-binary description of the phase relations. In the quasi-binary case, the $\mathrm{Mg}$ content can be used as a cursor for the solute level. ${ }^{[28,29]}$

At the same time, the natural aging and artificial aging models are connected to the work-hardening (i.e., cold deformation) and static recovery models through the matrix dislocation density $\rho$. In NaMo-Version 2, the parameter $\rho$ acts as an internal variable, which alters the kinetics of the precipitation reactions by changing the nucleation rate and the element diffusivity. Also in the extended artificial aging model, the rate controlling step is assumed to be diffusion of magnesium to the particle/matrix interface, analogous to that done in NaMo-Version 1. ${ }^{[20-22,28,29]}$ 
Table I. Nucleation Laws Implemented in NaMo-Version 2

\begin{tabular}{llll}
\hline Model & Expression for $j_{0}$ & Expression for $\Delta G^{*}$ & Adjustable Parameters \\
\hline NA-model (cluster formation) & $j_{0}^{c_{1}}\left(1-\rho / \rho_{c}\right)+\mathrm{j}_{0}^{\mathrm{c}_{2}}$ & $\frac{\left(A_{0}^{c}\right)^{3}}{\left(R T \ln \left(\bar{C} / C_{\mathrm{e}}^{\mathrm{Mg}}\right)-\Delta G_{\mathrm{s}}\right)^{2}}$ & $\begin{array}{c}j_{0}^{c_{1}}, j_{0}^{c_{2}} \text { and } A_{0}^{c}(\operatorname{since~the~other~} \\
\text { parameters are fixed) }\end{array}$ \\
AA-model (nucleation of $\beta^{\prime \prime}$ in Al matrix) & $j_{0}^{m}\left(1-\rho / \rho_{c}\right)$ & $\frac{\left(A_{0}^{m}\right)^{3}}{\left(R T \ln \left(\bar{C} / C_{\mathrm{e}}^{\mathrm{Mg}}\right)\right)^{2}}$ & $\begin{array}{c}\text { none (since } j_{0}^{m} \text { and } A_{0}^{m} \text { are the } \\
\text { same as in NaMo-version } 1)\end{array}$ \\
AA-model (nucleation of $\beta^{\prime}$ at dislocations) & $j_{0}^{d}$ & $\frac{\left(A_{0}^{d}\right)^{3}}{\left(R T \ln \left(\bar{C} / C_{\mathrm{e}}^{\mathrm{Mg}}\right)\right)^{2}}$ & $j_{0}^{d}$ and $A_{0}^{d}$ \\
\hline
\end{tabular}

The different symbols are defined in Appendix A.

The way the different models in NaMo-Version 2 are structured and coupled is further illustrated and elaborated below.

\section{Nucleation laws}

The nucleation law for $\beta^{\prime \prime}$ formation, as previously implemented in NaMo-Version 1, is derived from the general expression for the nucleation rate $j^{[46] \text {. }}$

$$
j=j_{0} \exp \left(-\frac{Q_{\mathrm{d}}}{R T}\right) \exp \left(-\frac{\Delta G^{*}}{R T}\right)
$$

where the parameters $j_{0}, Q_{\mathrm{d}}, R, T$, and $\Delta G^{*}$ have their usual meaning and are defined in Appendix A.

Also the new expressions for the nucleation rate being implemented in NaMo-Version 2 (and summarized in Table I) are based on Eq. [1], and the original constitutive equations are presented in Reference 10. However, these need to be further developed in order to accommodate the dislocation generation, the cluster formation, and the competitive nucleation of $\beta^{\prime \prime}$ and $\beta^{\prime}$ precipitates occurring during cold deformation, natural aging, and artificial aging, respectively. For example, in the new natural aging nucleation law, the misfit strain energy term $\Delta G_{\mathrm{s}}$ has been reintroduced in the expression for energy barrier for heterogeneous nucleation $\Delta G^{*}$ in Table I. This term is neglected in the nucleation laws for the hardening $\beta^{\prime \prime}$ and $\beta^{\prime}$ precipitates.

Based on atomistic modeling, it can be argued that $\Delta G_{\mathrm{s}}$ for cluster formation in Al-Mg-Si alloys should lie within the range from 1.1 to $7.7 \mathrm{~kJ} / \mathrm{mol} .^{[47]}$ Therefore, in NaMo-Version 2 a misfit strain energy of $2.7 \mathrm{~kJ} / \mathrm{mol}$ is used as a default value for $\Delta G_{\mathrm{s}}$, which fits well in with the other default parameter values employed in the model.

In addition, it is necessary to account for the effect of cold deformation. The dislocations generated will affect the nucleation process in different ways. First of all, they provide favorable sites for heterogeneous nucleation of $\beta^{\prime}$ precipitates during artificial aging. ${ }^{[48,49]}$ This requires a second artificial aging nucleation law and a new calibrated value for the pre-exponential factor in Eq. [1] (i.e., $j_{0}=j_{0}^{d}$ ). At the same time the dislocations act as sinks for excess vacancies and solute atoms. ${ }^{[50-52]}$ Hence, a precipitate-free zone (PFZ) will initially form around the dislocations when the matrix nucleation rate starts to decrease locally as a result of the depletion, as shown schematically in Figure 3.

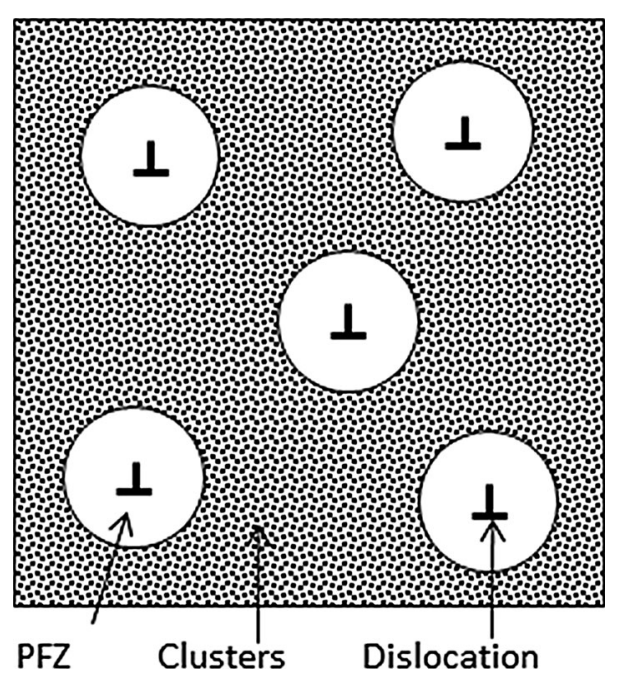

Fig. 3-Schematic illustration of how precipitate-free zones form around the dislocations during natural aging.

Since the pre-exponential factor in Eq. [1] scales with the total number of heterogeneous nucleation sites per unit volume being available for matrix nucleation, ${ }^{[53]}$ it is possible to relate $j_{0}$ directly to the matrix dislocation density $\rho$. For example, if one takes in the case of cluster formation $j_{0} \approx j_{0}^{c_{1}}$ when $\rho=0$ and $j_{0}=j_{0}^{c_{2}}$ when the critical dislocation density $\rho_{\mathrm{c}}$ for complete overlap of the PFZs is reached, the following relationship is obtained:

$$
j_{0}=j_{0}^{c_{1}}\left(1-\rho / \rho_{c}\right)+\mathbf{j}_{0}^{\mathrm{c}_{2}} .
$$

Nucleation of $\beta^{\prime \prime}$ precipitates during artificial aging in the presence of dislocations can be handled in a similar manner by taking $j_{0}^{m}$ and 0 as the upper and lower limit for the pre-exponential factor $j_{0}$ in the nucleation law, respectively. Table I summaries the different nucleation laws being implemented in $\mathrm{NaMo}$-Version 2.

In Figure 4 the competitive nucleation of $\beta^{\prime \prime}$ and $\beta^{\prime}$ precipitates which occurs during artificial aging in the presence of dislocations is illustrated more in detail. The form of the two nucleation laws listed in Table I implies that matrix nucleation of $\beta^{\prime \prime}$ will completely dominate at low dislocation densities, while nucleation of $\beta^{\prime}$ at dislocations is the overriding mechanism when $\rho \geq \rho_{\mathrm{c}}$. In-between, a narrow transition region exists, where both types of precipitates may form at the same time. 


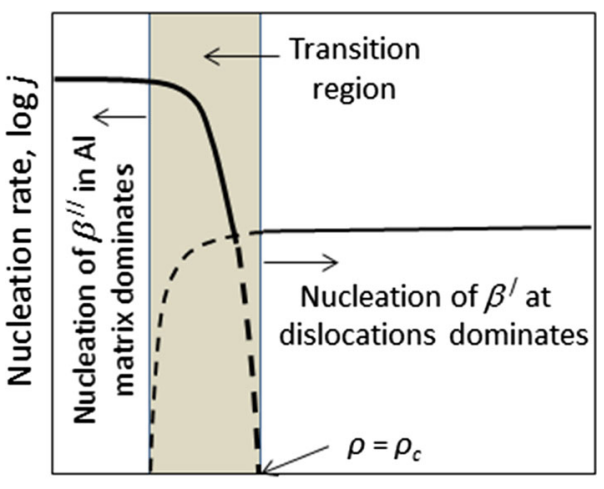

Dislocation density, $\log \rho$

(a)

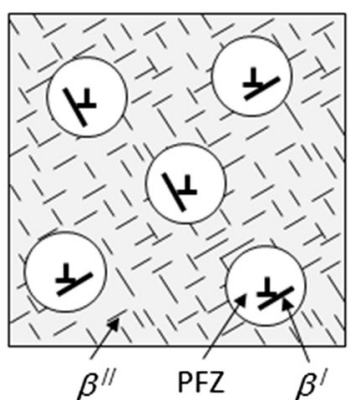

(b)

Fig. 4 -Schematic illustrations of competitive nucleation of $\beta^{\prime \prime}$ and $\beta^{\prime}$ particles during artificial aging in the presence of dislocations: $(a)$ the transition from matrix nucleation to nucleation at dislocations, as predicted by the artificial aging model in NaMo-Version 2, $(b)$ the resulting microstructure evolution when $\rho$ falls within the transition region.

This type of competitive nucleation is in good agreement with experimental observations. ${ }^{[48,49]}$

In $\mathrm{Al}-\mathrm{Mg}-\mathrm{Si}$ alloys the transition from matrix nucleation to nucleation at dislocations occurs at some point within the plastic strain interval between 0 and 10 pct. ${ }^{[48,49]}$ However, since the exact threshold value for $\rho$ at which the matrix nucleation ceases is not known, a reasonable default value for the critical dislocation density is instead implemented in the numerical code and used throughout the simulations (i.e., $\rho_{\mathrm{c}}=2.0 \times 10^{13} \mathrm{~m}^{-2}$ ).

\section{B. Growth Laws}

Table II summarizes the two growth laws being implemented in NaMo-Version 2. In the natural aging model, which assumes interface controlled growth, the cluster evolution at RT is calculated from the standard expression relating $\mathrm{d} r / \mathrm{d} t$ to the mean solute concentration $\bar{C}$ and the interface concentration of magnesium $C_{\mathrm{i}}^{\mathrm{Mg}\left[{ }^{[42]}\right.}$ Because the value of $C_{\mathrm{i}}^{\mathrm{Mg}}$ is updated at each time-step during the simulations via the extended thermodynamic model and the Gibbs-Thomson equation, the rate law also describes the subsequent reversion of the clusters during artificial aging. This corresponds to the situation where $C_{\mathrm{i}}^{\mathrm{Mg}}>\bar{C}$ and $\mathrm{d} r / \mathrm{d} t$ becomes negative. At the same time the temperature dependence of the reaction rate is captured by an Arrhenius type of relationship, employing published data for the pre-exponential mobility term $M_{0}$ and the activation energy $Q_{\mathrm{d}}$ for magnesium diffusion across the cluster/matrix interface. ${ }^{[42]}$ These are used as default values in the numerical code.

In the extended artificial aging model, where diffusion controlled growth is assumed, the original rate law from NaMo-Version 1 has been implemented. ${ }^{[20,29]}$ The only difference is the expression for the magnesium diffusion coefficient, which in NaMo-Version 2 is modified in order to allow for pipe diffusion through the dislocation core following cold deformation. In this case, the relationship between the effective diffusion coefficient $D_{\text {eff }}^{\mathrm{Mg}}$, the bulk diffusion coefficient $D^{\mathrm{Mg}}$, the core diffusion coefficient $D_{\mathrm{c}}^{\mathrm{Mg}}$, and the matrix dislocation density $\rho$ is identical to the one used by others and frequently quoted in the scientific literature. ${ }^{[53,54]}$ Hence, all necessary input data for the cross-sectional area $a_{c}$ of the pipes and the temperature dependence of $D^{\mathrm{Mg}}$ and $D_{\mathrm{c}}^{\mathrm{Mg}}$ can be obtained from well-established sources and used as default values in the numerical code. ${ }^{[54]}$

\section{Continuity equation}

In NaMo-Version 1, the continuity equation, which relates the mean solute concentration $\bar{C}$ to the nominal $\mathrm{Mg}$ content in the alloy $C_{0}^{\mathrm{Mg}}$ and the amount of magnesium being tied-up in the precipitates $C_{\mathrm{p}}^{\mathrm{Mg}}$, is based on the assumption that all precipitates have identical chemical composition (i.e., $\mathrm{Mg}_{5} \mathrm{Si}_{3}$ ) and mass density. ${ }^{[20-22,28,29]}$ Because these approximations largely simplify the mass balance without contributing to loss of predictive power, ${ }^{[21,22,28,29]}$ they are also incorporated in the new continuity equation being implemented in NaMo-Version 2. Still, the equation needs to be modified in order to allow for the use of two separate particle size distributions:

Table II. Growth Laws Implemented in NaMo-Version 2

\begin{tabular}{lll}
\hline Model & Expression for the Growth Rate & Adjustable Parameters \\
\hline NA-model (cluster formation) & $\frac{\mathrm{d} r}{\mathrm{~d} t}=M_{0} \exp \left(-\frac{Q_{d}}{R T}\right)\left(\bar{C}-C_{\mathrm{i}}^{\mathrm{Mg}}\right)$ & none (since $M_{0}$ and $Q_{d}$ are fixed) \\
AA-model (nucleation of $\beta^{\prime \prime}$ & $\frac{\mathrm{d} r}{\mathrm{~d} t}=\left(\frac{\bar{C}-C_{i}^{\mathrm{Mg}}}{C_{\mathrm{p}}^{\mathrm{Mg}}-C_{i}^{\mathrm{Mg}}}\right)\left(\frac{D_{\mathrm{eff}}^{\mathrm{Mg}}}{r}\right)$ & none (since $a_{c}$ and $D_{\mathrm{c}}^{\mathrm{Mg}}$ are fixed) \\
in Al matrix and nucleation of $\beta^{\prime}$ at dislocations) & where & $D_{\mathrm{eff}}^{\mathrm{Mg}}=D^{\mathrm{Mg}}\left[1+\left(\rho \mathrm{a}_{\mathrm{c}} \frac{\mathrm{D}_{\mathrm{c}}^{\mathrm{Mg}}}{\mathrm{D}^{\mathrm{Mg}}}\right)\right]$ \\
\hline
\end{tabular}

The different symbols are defined in Appendix A. 


$$
\bar{C}=C_{0}^{\mathrm{Mg}}-\left(C_{\mathrm{p}}^{\mathrm{Mg}}-\bar{C}\right)\left(\sum_{i} \frac{4}{3} \pi r_{i}^{3} N_{i}+\sum_{\mathrm{j}} \frac{4}{3} \pi \mathrm{r}_{\mathrm{j}}^{3} \mathrm{~N}_{\mathrm{j}}\right) .
$$

In Eq., [3] the volume fraction of clusters and hardening precipitates are calculated individually via separate summation formulae. However, since all particles are assumed to have the same $\mathrm{Mg}$ content, their volume fraction $f$ can alternatively be computed from the composition parameters $C_{0}^{\mathrm{Mg}}, \bar{C}$ and $C_{\mathrm{p}}^{\mathrm{Mg}}$ :

$$
f=\frac{C_{0}^{\mathrm{Mg}}-\bar{C}}{C_{p}^{\mathrm{Mg}}-\bar{C}} .
$$

From this relationship, it is evident that the continuity equation is actually a "lever rule," which takes into account the inherent constraints provided by the phase diagrams.

2. Correction term for the reduced thermodynamic stability of clusters

In NaMo-Version 2, the thermodynamic model providing input data for $C_{\mathrm{e}}^{\mathrm{Mg}}$ and $C_{\mathrm{i}}^{\mathrm{Mg}}$ to the extended artificial aging model is identical to the one used in Version 1 and outlined in Figure 1(b). As already stated, this is a simplified quasi-binary description of the phase relations within the Al-rich corner of the ternary $\mathrm{Al}-\mathrm{Mg}-\mathrm{Si}$ phase diagram. ${ }^{[28,29]}$ Because corresponding data for the metastable phases also exist, ${ }^{[55]}$ the same approach can be employed to capture the thermodynamic solvus temperatures for the clusters which form during natural aging as a function of the $\mathrm{Mg}$ content. If the reported values for the stable $\alpha$-Al- $\beta$ system are used as a starting point for the curve fitting, the following general expression for $C_{\mathrm{e}}^{\mathrm{Mg}}$ is obtained ${ }^{[28]}$.

$$
\begin{aligned}
C_{\mathrm{e}}^{\mathrm{Mg}}(\text { wt pct }) & =C_{\mathrm{s}} \exp \left(-\frac{Q_{\mathrm{s}}}{R T}\right) \\
& =290 \exp \left(-\frac{\left(41000-\Omega_{\mathrm{c}}\right)}{R T}\right),
\end{aligned}
$$

where $\Omega_{\mathrm{c}}$ is a correction term which accounts for the reduced thermodynamic stability of the clusters compared with the other stable and metastable phases (i.e., $\beta, \beta^{\prime}$, and $\beta^{\prime \prime}$ ).

It follows from Eq. [5] that the hardening $\beta^{\prime}$ and $\beta^{\prime \prime}$ precipitates are characterized by the same apparent solvus boundary enthalpy $Q_{\mathrm{s}}$ as the equilibrium $\beta$ phase. Hence, it is implicitly assumed that their reduced thermal stability compared to $\beta$ is solely due to a smaller particle size. ${ }^{[3,21,28]}$ In contrast, the clusters, which exhibit a highly different chemistry and atomic structure, will have their own equilibrium solvus within the phase diagram. This is allowed for through the $\Omega_{\mathrm{c}}$ parameter in the expression for $Q_{\mathrm{s}}$.

In the present study, $\Omega_{\mathrm{c}}$ has been determined by calibrating Eq. [5] to the data reported for cluster formation in Al-Mg-Si alloys. ${ }^{[55]}$ In NaMo-Version 2, a default value of $18.3 \mathrm{~kJ} / \mathrm{mol}$ is used for this specific parameter.

Based on Eq. [5] the magnesium concentration at the cluster/matrix interface $C_{\mathrm{i}}^{\mathrm{Mg}}$ during evolution can be calculated via the Gibbs-Thomson relation, analogous to that done in NaMo-Version 1 for the hardening $\beta^{\prime \prime}$ and $\beta^{\prime}$ precipitates ${ }^{[20-22,28,29]}$ :

$$
C_{\mathrm{i}}^{\mathrm{Mg}}=C_{\mathrm{e}}^{\mathrm{Mg}} \exp \left(\frac{2 \gamma_{\mathrm{c}} V_{\mathrm{m}}}{r R T}\right) .
$$

In Eq. [6] the molar volume $V_{\mathrm{m}}$ of the clusters is assumed to be constant and equal to the value used for the hardening precipitates in NaMo-Version 1 (i.e., $\left.7.62 \times 10^{-5} \mathrm{~m}^{3} / \mathrm{mol}\right) .^{[21,22,28,29]}$ Then, when $V_{\mathrm{m}}$ is fixed, the cluster/matrix interfacial energy $\gamma_{c}$ is adjusted so that Eq. [6] yields realistic outputs for $C_{\mathrm{i}}^{\mathrm{Mg}}$ at the same time as its numerical value lies within the range reported for clusters in $\mathrm{Al}-\mathrm{Mg}-\mathrm{Si}$ alloys. ${ }^{[55]}$ In NaMo-Version 2, an interfacial energy of $0.02 \mathrm{~J} / \mathrm{m}^{2}$ is used as a default value for $\gamma_{c}$, reflecting the coherent nature of the clusters.

\section{Evolution equations for the dislocation density}

The cold deformation model referred to in Figure 2 is a stripped version of the work-hardening model outlined in Figure 1(d). It follows from Figure 2 that cold deformation is assumed to occur instantaneously at some point during the natural aging process. Under such conditions, the alloy is predominantly in the solid solution state, which means that the imposed plastic strain $\varepsilon_{\mathrm{p}}$ will contribute to an increase in the number density of the statistically stored dislocations $\rho_{\mathrm{s}}$ (and thus $\rho$ ), according to the relationship ${ }^{[22,29]}$.

$$
\rho=\rho_{\mathrm{s}}=\left(\frac{k_{1}}{k_{2}}\right)^{2}\left(1-\exp \left(-\frac{k_{2} \varepsilon_{\mathrm{p}}}{2}\right)\right)^{2} .
$$

In Eq. [7] the $k_{1}$ parameter is characteristic of the material under consideration, whereas $k_{2}$, which determines the rate of dynamic recovery during plastic deformation, depends on the actual solute content in the alloy. Appropriate input data for $k_{1}$ and $k_{2}$, which can serve as default values in the numerical code, have been reported elsewhere. ${ }^{[22,29]}$

During subsequent artificial aging, the dislocation density $\rho$ being initially established as a result of the cold deformation becomes gradually reduced due to static recovery processes occurring at elevated temperatures. ${ }^{[34]}$ In NaMo-Version 2, the static recovery model of Nes et al. ${ }^{[34-36]}$ has been adopted to capture the dislocation annihilation. In this case, the recovery rate $\mathrm{d} \rho / \mathrm{d} t$ is conveniently described by the following evolution equation:

$$
\mathrm{d} \rho / \mathrm{d} t=-k_{3} \rho^{3 / 2} \exp \left(-\frac{U_{\mathrm{s}}}{R T}\right) \sinh \left(\frac{k_{4} \sqrt{\rho}}{R T}\right),
$$

where $U_{\mathrm{s}}$ is the average activation energy for the solute diffusion constricting the dislocation movement, as defined in References 35, 36 
In Eq. [8] both $k_{3}$ and $k_{4}$ are fitting parameters, which must be determined separately by calibrating the static recovery model to experimental data. Still, the constants have a clear physical meaning in the context of static recovery, since they contain the other parameters being embedded in the original expression for $\mathrm{d} \rho / \mathrm{d} t .^{[34-36]}$

In NaMo-Version 2, the data reported by Furu et $a l .^{[56]}$ have been used as a basis for the calibration, yielding the default values $k_{3}=5.68 \mathrm{~m} / \mathrm{s}$ and $k_{4}=0.0048 \mathrm{Jm} / \mathrm{mol}$ for these fitting parameters.

\section{Framework for calculating the macroscopic yield strength}

In the original yield strength model, all particles are assumed to be spherical. ${ }^{[2-22,28,29]}$ Hence, the mathematical derivation of the equations describing the underlying particle-dislocation interactions is done in line with this assumption. Since the hardening $\beta^{\prime \prime}$ and $\beta^{\prime}$ precipitates in Al-Mg-Si alloys are either needle- or rod-shaped being orientated in different $\langle 100\rangle$ directions, ${ }^{[31,48]}$ the general applicability of such an idealized yield strength model is not obvious. Still, it can be argued that the approximation of spherical particles is a reasonable one, also in the case where the precipitates actually are rod-shaped, as long as the yield strength model is calibrated before use against experimental data, as done in NaMo-Version 1. This follows from the mathematical treatment provided in Appendix B. Therefore, the original framework of the yield strength model is still valid and can safely be transferred to the next generation of NaMo as well.

Nevertheless, the introduction of the room-temperature storage and the cold deformation process stages in NaMo-Version 2 requires some modifications of the yield strength model. First of all, the contribution from dislocation hardening $\sigma_{\mathrm{d}}$ must be incorporated in the expression for the overall macroscopic yield strength $\sigma_{\mathrm{y}}$. This contribution can generally be written as ${ }^{[57]}$

$$
\sigma_{\mathrm{d}}=\alpha M G b \sqrt{\rho}
$$

where $\alpha$ is a constant, $M$ is the Taylor factor, $G$ is the shear modulus, and $b$ is the Burgers vector. Appropriate default values for these parameters can be obtained from well-established sources. ${ }^{[21,22,28-33,57]}$

In addition, the new yield strength model must be flexible enough to handle local variations in the mechanical properties caused by crystallographic texture, both with respect to orientation within a given aluminum plate or extrusion as well as between different aluminum alloys exhibiting either a recrystallized or a subgrain type of microstructure. ${ }^{[58]}$ In NaMo-Version 2, this is done by allowing the Taylor factor to become an input variable rather than a default parameter in the yield strength model. Thus, if one assumes that the different strength contributions can be added linearly in stress space as in NaMo-Version $1,{ }^{[21,22,28,29]}$ the new expression for $\sigma_{\mathrm{y}}$ becomes:

$$
\sigma_{\mathrm{y}}=\frac{M}{M_{\mathrm{r}}}\left(\sigma_{\mathrm{i}}+\sigma_{\mathrm{ss}}+\sigma_{\mathrm{p}}+\sigma_{\mathrm{d}}\right),
$$

where $\sigma_{\mathrm{i}}$ denotes the intrinsic yield strength of pure aluminum, while $\sigma_{\mathrm{ss}}$ and $\sigma_{\mathrm{p}}$ represent the strength contribution from elements in solid solution and hardening precipitates, respectively. Note that the justification of implementing Eq. [10] in NaMo-Version 2 relies solely on the fact that it has proved to work well in many other situations, ${ }^{[21-29,42,48]}$ since the assumption of linear additive strength contributions is just one of several possible options to choose from when calculating $\sigma_{\mathrm{y} \cdot}{ }^{[1,2,65]}$

In the original yield strength model, a constant Taylor factor of 3.1 is assumed when calculating $\sigma_{\mathrm{y}}{ }^{[20-22,28,29]}$ This value, which is typical for alloys with randomly oriented grains, ${ }^{[59]}$ will therefore serve as the reference Taylor factor $M=M_{\mathrm{r}}$ in the modified yield strength model and be used as a basis for calibrating the unknown numerical constants embedded in the expressions for $\sigma_{\mathrm{ss}}$ and $\sigma_{\mathrm{p}}$. Then, in a calibrated form, Eq. [10] can be employed to simulate how different starting microstructures and deformation textures affect the resulting mechanical properties, provided that appropriate input values for the Taylor factor are available through experiments or simulations. ${ }^{[60]}$

In commercial Al-Mg-Si alloys, the alloying elements contributing to solid solution hardening are mainly magnesium, silicon, manganese, and copper. Since the nominal content of each of these elements is well below the solubility limit at all relevant solution temperatures, permanent solute loss by precipitation of constituent phases like pure $\mathrm{Si}, \mathrm{Al}_{3} \mathrm{Mg}_{2} . \mathrm{Al}_{12} \mathrm{Mn}$ etc., can be ignored. However, because $\mathrm{Si}$ and $\mathrm{Mn}$ will react with $\mathrm{Fe}$ to form the intermetallic compound $\alpha-\mathrm{Al}_{15}(\mathrm{Fe}, \mathrm{Mn})_{3} \mathrm{Si}_{2}$ during solidification and homogenisation, ${ }^{[61,62]}$ it is necessary to correct for this when calculating their matrix concentrations and subsequent contribution to solid solution hardening. In NaMoVersion 1, this strength contribution is computed via the equation ${ }^{[63,64]}$ :

$$
\sigma_{\mathrm{ss}}=\sum_{k} k_{\mathrm{k}} C_{\mathrm{k}}^{2 / 3},
$$

where $C_{\mathrm{k}}$ is the concentration of a specific alloying element in solid solution and $k_{\mathrm{s}}$ is the corresponding scaling factor in which the Taylor factor also is embedded.

Taking now 0.5 as the best estimate of the effective distribution coefficient of $\mathrm{Mn}$ in the as-homogenized Al-Mg-Si alloys, ${ }^{[62]}$ the following new expressions are obtained for the concentrations of manganese $C_{\mathrm{ss}}^{\mathrm{Mn}}$ and silicon $C_{\mathrm{ss}}^{\mathrm{Si}}$ in solid solution:

$$
\begin{gathered}
C_{\mathrm{ss}}^{\mathrm{Mn}}=0.5 C_{0}^{\mathrm{Mn}}, \\
C_{\mathrm{ss}}^{\mathrm{Si}}=C_{0}^{\mathrm{Si}}-0.33\left(C_{0}^{\mathrm{Fe}}+0.5 C_{0}^{\mathrm{Mn}}\right),
\end{gathered}
$$

where $C_{0}^{\mathrm{Mn}}, C_{0}^{\mathrm{Si}}$, and $C_{0}^{\mathrm{Fe}}$ refer to the nominal concentrations of the same elements in the alloy.

In NaMo-Version 2, these refined expressions for $C_{\mathrm{ss}}^{\mathrm{Mn}}$ and $C_{\mathrm{ss}}^{\mathrm{Si}}$ have been implemented in the modified yield 
Table III. Summary of Relevant Sub-Equations Used to Calculate $\sigma_{p}$ in Modified Yield Strength Model

\begin{tabular}{|c|c|c|c|}
\hline \multirow[b]{2}{*}{ Parameter } & \multicolumn{2}{|c|}{ Sub-Equations } & \multirow[b]{2}{*}{ Adjustable Parameters } \\
\hline & Clusters & Hardening precipitates & \\
\hline$\sigma_{p}$ & $\sigma_{p 1}=\frac{M_{r} \overline{F_{1}}}{b \ell_{1}}$ & $\sigma_{p 2}=\frac{M_{r} \overline{F_{2}}}{b \ell_{2}}$ & None (since $M_{r}$ and $b$ are fixed) \\
\hline $\bar{F}$ & $\begin{array}{l}\overline{F_{1}}=\frac{\sum_{i} N_{i} F_{i}}{\sum_{i} N_{i}} \\
\text { where } \\
F_{i}=2 \beta_{1} G b^{2}\left(\frac{r_{i}}{r_{c 1}}\right)^{\dagger}\end{array}$ & $\begin{array}{l}\quad \overline{F_{2}}=\frac{\sum_{j} N_{j} F_{j}}{\sum_{j} N_{j}} \\
\text { where } \\
F_{j}=2 \beta_{1} G b^{2}\left(\frac{r_{j}}{r_{c 2}}\right)^{\dagger \dagger}\end{array}$ & $\begin{array}{l}r_{c 1} \text { and } \beta_{1} \text { (since the other parameters } \\
\text { are the same as in NaMo-Version } 1)\end{array}$ \\
\hline$\ell$ & $\ell_{1}=\left(\frac{N_{v 1} \overline{r_{1}} \overline{F_{1}}}{\beta_{1} G b^{2}}\right)^{-1 / 2}$ & $\ell_{2}=\left(\frac{N_{v_{2}} \overline{F_{2}} \overline{F_{2}}}{\beta_{1} G b^{2}}\right)^{-1 / 2}$ & None (when $r_{c 1}$ and $\beta_{1}$ are fixed) \\
\hline
\end{tabular}

Table IV. Chemical Composition of Alloy Used for Calibration and Validation of NaMo-Version 2

\begin{tabular}{lccccccc}
\hline Alloy & $\mathrm{Si}$ & $\mathrm{Mg}$ & $\mathrm{Cu}$ & $\mathrm{Mn}$ & $\mathrm{Fe}$ & $\mathrm{Others}$ & $\mathrm{Al}$ \\
\hline AA6005 & 0.60 & 0.59 & 0.13 & 0.09 & 0.22 & - & balance \\
\hline
\end{tabular}

Table V. Summary of Testing Program in Series A Covering the First Two Cold Deformation and Natural Aging Process Stages

\begin{tabular}{lccc}
\hline Series No. & Plastic Strain (Pct) & Storage Time $t_{1}($ At RT) & Storage Time $t_{2}($ At RT) \\
\hline A1 & 0 & from 1 min to 1 week & 0 \\
A2 & 2 & 1 min & 1 hour, 1 week, 2 months \\
A3 & 2 & 6 hours & 1 hour, 1 week, 2 months \\
A4 & 2 & 1 week & 1 hour, 1 week, 2 months \\
A5 & 10 & 1 min & 1 hour, 1 week, 2 months \\
A6 & 10 & 6 hours & 1 hour, 1 week, 2 months \\
A7 & 10 & 1 week & 1 hour, 1 week, 2 months \\
\hline \multicolumn{2}{l}{ The different symbols are defined in Appendix A. }
\end{tabular}

Table VI. Summary of Testing Program in Series B Covering Both the Cold Deformation, the Natural Aging, and the Artificial Aging Process Stages

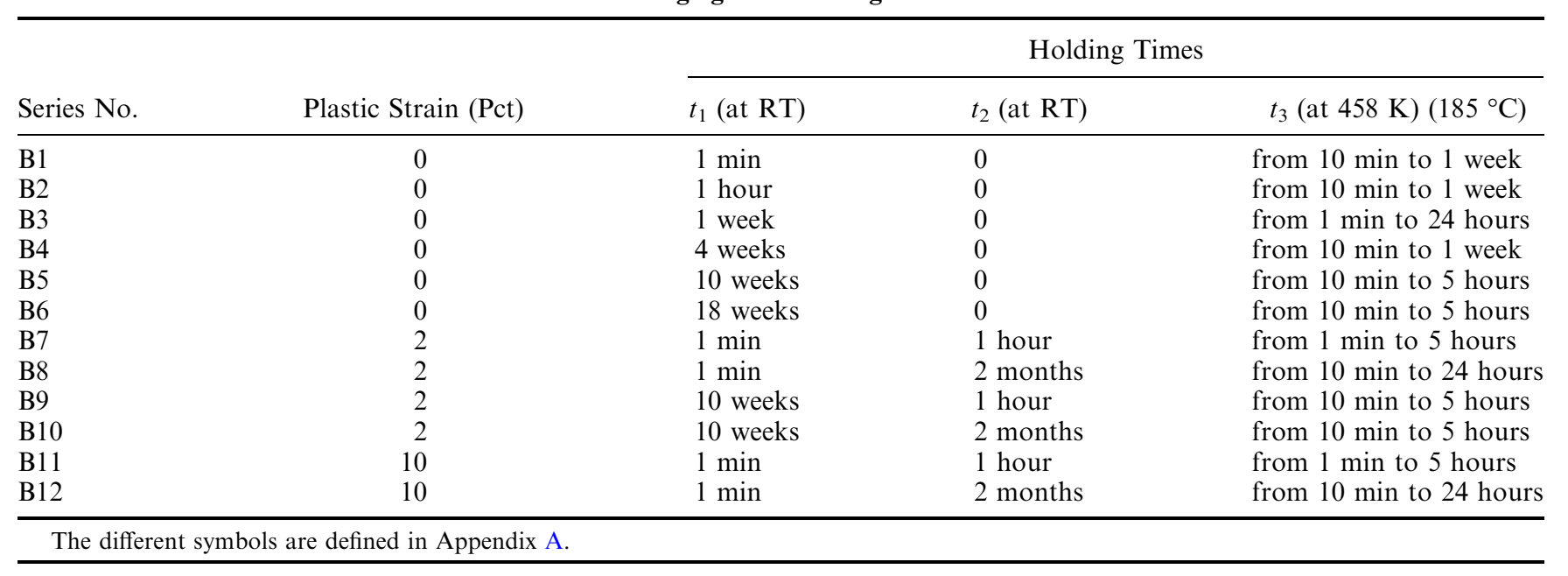


strength model and used as a basis for re-calibrating the scaling factors for $\mathrm{Mg}, \mathrm{Si}, \mathrm{Mn}$, and $\mathrm{Cu}$ in Eq. [11] Thus, by employing the experimental data reported by Myhr et al., ${ }^{21]}$ the following set of new and self-consistent default values are obtained when $M=M_{\mathrm{r}}$ : $k_{\mathrm{Cu}}=46.4 \mathrm{MPa} / \mathrm{wt} \mathrm{pct}^{2 / 3}, \quad k_{\mathrm{Mg}}=15.0 \mathrm{MPa} / \mathrm{wt} \mathrm{pct}^{2 / 3}$, $k_{\mathrm{Mn}}=80.0 \mathrm{MPa} / \mathrm{wt} \mathrm{pet}^{2 / 3} \quad$ and $\quad k_{\mathrm{Si}}=33.0 \mathrm{MPa} /$ wt $\mathrm{pct}^{2 / 3}$.

Finally, since NaMo-Version 2 deals with two particle size distributions, there is a need to slightly alter the calculation procedure when evaluating $\sigma_{\mathrm{p}}$. The first step is to calculate the strength contribution from each population separately, similar to that done in NaMoVersion 1 for the mono-population case. Then the two individual contributions $\sigma_{\mathrm{p} 1}$ and $\sigma_{\mathrm{p} 2}$ are added together in a non-linear manner via the relationship ${ }^{[65]}$.

$$
\sigma_{\mathrm{p}}=\sqrt{\left(\sigma_{\mathrm{p} 1}\right)^{2}+\left(\sigma_{\mathrm{p} 2}\right)^{2}}
$$

where symbols with subscripts $i$ or 1 and $j$ or 2 now refer to clusters (with distribution parameters $N_{i}, r_{i}, N_{v 1}$, and $\overline{r_{1}}$ ) and hardening $\beta^{\prime \prime}$ and $\beta^{\prime}$ precipitates (with distribution parameters $N_{j}, r_{j}, N_{v 2}$, and $\overline{r_{2}}$ ), respectively.

In each case, the mean obstacle strength $\bar{F}$ and the mean effective particle spacing in the slip plane along the bending dislocation $\ell$ are computed using the same formalism and methodology as described in Reference 65. These parameters determine the numerical values of $\sigma_{\mathrm{p} 1}$ and $\sigma_{\mathrm{p} 2}$ in Eq. [14]. The different sub-equations used in the calculations are summarized in Table III.

The basic idea behind the approach will now be explained more in detail. From a modeling point of view, the implementation of a common physical framework in NaMo-Version 2 for capturing the particle strength contribution is considered to be a great advantage, since the same yield strength model then can be employed for both clusters and hardening precipitates without having to calibrate the adjustable parameters twice. But by doing so one implicitly assumes that also the clusters will ultimately convert into Orowan particles at some critical radius $r_{\mathrm{c} 1}$, which, of course, is physically unreasonable. Still, it is possible to use $r_{\mathrm{c} 1}$ as a scaling parameter in the yield strength model as long as the actual cluster size is significantly smaller and shearing by dislocations is the dominating strengthening mechanism. In that case, the yield strength model will just contain two unknown adjustable parameters which need to be fixed by calibration, as indicated in Table III, i.e., the critical radius $r_{\mathrm{c} 1}$ defining the hypothetical transition from shearing to bypassing of the clusters by dislocations and the $\beta_{1}$ factor in the expressions for $F_{i}$ and $F_{j}$. The other ones have exactly the same default values as in NaMoVersion 1. ${ }^{[20-22]}$

\section{EXPERIMENTAL}

The experiments referred to in the present investigation were conducted on an AA 6005 alloy sheet with chemical composition as shown in Table IV. The sheet was produced on a commercial production line at the AluNorf rolling mill in Norf, Germany, where the direct chill (DC) cast ingot with rectangular cross section was subjected to reverse hot-rolling and subsequent coldrolling in several passes down to the final gage thickness of $1.15 \mathrm{~mm}$.

\section{A. Heat Treatment and Cold Deformation Schedules}

A comprehensive experimental program was then undertaken by Hydro Research and Development in Bonn, Germany to evaluate the mechanical response of the sheet material to different cold deformation and heat treatment schedules. First the samples were solution heat treated at $833 \mathrm{~K}\left(560^{\circ} \mathrm{C}\right)$ for 5 minutes in a fluidized sand bed, employing a constant heating rate of $12 \mathrm{~K} / \mathrm{s}$. During the operation, the maximum temperature fluctuation was measured to be $\pm 2 \mathrm{~K}$.

After water quenching to RT, the specimens were subjected to various combinations of successive natural aging, cold deformation, and artificial aging treatments, according to the overall testing program outlined in Tables V (Series A) and VI (Series B). In Series A, both individual and combined effects of cold deformation and natural aging are examined, using uniaxial tensile testing to achieve the target pre-straining levels of 2 and 10 pct, respectively. The subsequent mechanical response of the cold-deformed and/or naturally aged materials to artificial aging is dealt with in Series B. These aging experiments were carried out at a constant temperature of $458 \mathrm{~K}\left(185^{\circ} \mathrm{C}\right)$ in an air circulating furnace.

\section{B. Tensile Testing}

The samples used for tensile testing were manufactured according to German standard DIN 50125 for flat specimens - all having a gage length of $80 \mathrm{~mm}$, a rectangular cross section of $32 \mathrm{~mm} \times 1.15 \mathrm{~mm}$, and a total length of $250 \mathrm{~mm}$. These samples were orientated with their tensile axis normal to the plate rolling direction.

The subsequent mechanical testing was performed in accordance with German standard DIN EN ISO 6892, using a commercial tensile testing machine equipped with a high-resolution extensometer. Measurements of the Young's modulus and the $R_{p 0.2}$ offset yield strength were performed at a constant nominal strain rate of $2.5 \times 10^{-4} 1 / \mathrm{s}$, whereas the final testing (i.e., from 4 pct plastic deformation and upwards) was done at a strain rate of $6.67 \times 10^{-3} 1 / \mathrm{s}$.

\section{Supplementary DSC and TEM Investigations}

Supplementary differential scanning calorimetry (DSC) and transmission electron microscope (TEM) investigations of selected pre-deformed and heat treated specimens have also been carried out in parallel with this modeling work at the Helmholtz Centre Berlin for Materials and Energy, Germany for Hydro Aluminium as an extension of Liang's doctoral thesis (see Reference 41). However, because these results are only used for calibration and validation purposes, the supplementary 
DSC and TEM investigations are not incorporated in the experimental program. Instead, the quoted research report in Reference 41 serves as a source reference along with the thesis work.

\section{CALIBRATION PROCEDURE}

Because NaMo-Version 2 contains many different input parameters which must be fixed before a prediction can be made, a special methodology (or calibration strategy) has been worked out in parallel with the on-going model development in order to deal with this problem.

\section{A. Default Parameter Values}

The main idea behind the calibration strategy is that the parameter values serving as defaults in the program should primarily be settled based on what is already known in the scientific literature. If such source data are not readily available (e.g., cannot be obtained from $\mathrm{NaMo-Version} 1$ or elsewhere), they must alternatively be obtained by calibrating the constitutive equations against dedicated experimental data. The way this is done will be described later.

When selecting the data due care has been taken to ensure that the chosen default values are physically reasonable and mutually consistent as well as traceable through well-established sources. By maximizing the use of such independent literature data, it is possible to reduce the total number of real fitting parameters in the model to an absolute minimum. This, in turn, makes the final calibration manageable.

Table VII summarises the different default parameter values used in NaMo-Version 2, which actually are a compilation of the input data presented earlier throughout the text.

\section{B. Determination of Adjustable Parameters in Nucleation Laws}

The next step is to determine the remaining adjustable parameters in the nucleation laws, using
Table VII. Summary of Default Parameter Values Used in NaMo-Version 2

\begin{tabular}{|c|c|c|}
\hline Parameter & Value & $\operatorname{Ref}^{\dagger}$ \\
\hline$a_{c}\left(\mathrm{~m}^{2}\right)$ & $1.0 \times 10^{-18}$ & {$[53]$} \\
\hline$b(\mathrm{~m})$ & $2.84 \times 10^{-10}$ & [67] \\
\hline$A_{0}^{m}(\mathrm{~kJ} / \mathrm{mol})$ & 18 & [21] \\
\hline$C_{\mathrm{p}}^{\mathrm{Mg}}($ wt pct) & 59 & {$[21]$} \\
\hline$D_{0}^{\mathrm{Mg}}\left(\mathrm{m}^{2} / \mathrm{s}\right)$ & $2.2 \times 10^{-4}$ & {$[21,68]$} \\
\hline$D_{C_{0}}^{\mathrm{Mg}}\left(\mathrm{m}^{2} / \mathrm{s}\right)$ & $1.0 \times 10^{-4}$ & {$[21,54]$} \\
\hline$G(\mathrm{GPa})$ & 27 & {$[67]$} \\
\hline$\Delta G_{s}(\mathrm{~kJ} / \mathrm{mol})$ & 2.7 & {$[47]$} \\
\hline$j_{0}^{m}\left(\# / \mathrm{m}^{3} \mathrm{~s}\right)$ & $3.07 \times 10^{36}$ & {$[21]$} \\
\hline$k_{1}\left(\mathrm{~m}^{-1}\right)$ & $4.0 \times 10^{8}$ & [22] \\
\hline$k_{2}$ & $C$-dependent & [22] \\
\hline$k_{3}(\mathrm{~m} / \mathrm{s})$ & 5.68 & {$[56]$} \\
\hline$k_{4}(\mathrm{Jm} / \mathrm{mol})$ & 0.0048 & [56] \\
\hline$k_{C u}\left(\mathrm{MPa} / \mathrm{wt} \mathrm{pct}^{2 / 3}\right)$ & 46.4 & [21] \\
\hline$k_{M g}\left(\mathrm{MPa} / \mathrm{wt} \mathrm{pct}^{2 / 3}\right)$ & 15.0 & {$[21]$} \\
\hline$k_{M n}\left(\mathrm{MPa} / \mathrm{wt} \mathrm{pct}^{2 / 3}\right)$ & 80.0 & [21] \\
\hline$k_{S i}\left(\mathrm{MPa} / \mathrm{wt} \mathrm{pct}^{2 / 3}\right)$ & 33.0 & [21] \\
\hline$M_{r}$ & 3.1 & {$[21,22]$} \\
\hline$M_{0}(\mathrm{~m} / \mathrm{s}$ wt pct $)$ & 6000 & [32] \\
\hline$Q_{c}(\mathrm{~kJ} / \mathrm{mol})$ & 90 & [53] \\
\hline$Q_{d}(\mathrm{~kJ} / \mathrm{mol})$ & 130 & {$[21,68]$} \\
\hline$r_{c 2}(\mathrm{~m})$ & $5.0 \times 10^{-9}$ & {$[21,69]$} \\
\hline$U_{s}(\mathrm{~kJ} / \mathrm{mol})$ & 160 & {$[35]$} \\
\hline$V_{m}\left(\mathrm{~m}^{3} / \mathrm{mol}\right)$ & $7.62 \times 10^{-5}$ & {$[21]$} \\
\hline$\alpha$ & 0.30 & [57] \\
\hline$\gamma_{c}\left(\mathrm{~J} / \mathrm{m}^{2}\right)$ & 0.02 & {$[70]$} \\
\hline$\Omega_{c}(\mathrm{~kJ} / \mathrm{mol})$ & 18.3 & {$[55]$} \\
\hline$\rho_{c}\left(\# / \mathrm{m}^{2}\right)\left(\right.$ value at $\left.\varepsilon_{p}=0.025\right)$ & $2.0 \times 10^{13}$ & [22] \\
\hline$\sigma_{i}(\mathrm{MPa})$ & 10 & {$[52]$} \\
\hline
\end{tabular}

The different symbols are defined in Appendix A.

${ }^{\dagger}$ Reference to source or source data used for calibration.

reflects the characteristic low equilibrium solvus of the clusters compared to the other phases, corresponding to $\Omega_{\mathrm{c}}=18.3 \mathrm{~kJ} / \mathrm{mol}$ in Eq. [5]. If the most general expression for $\Delta G^{*}$ in Table $\mathrm{I}$ is used as a starting point for the derivation, it is possible to obtain an explicit solution for the $A_{0^{-}}^{\mathrm{c}}$ parameter when $T=T_{\mathrm{c}}^{*}$ by differentiating Eq. [1] with respect to temperature and then equating to zero. ${ }^{[21]}$ In the correct (extended) form, it should read:

$$
A_{0}^{c}=\left[\frac{Q_{d}\left(R T_{c}^{*}\right)^{2}}{2\left(Q_{s} / R T_{c}^{*}\right)\left[\ln \left(\frac{C_{0}^{\mathrm{Mg}}}{C_{e}^{\mathrm{Mg}}}\right)-\frac{\Delta G_{s}}{R T_{c}^{*}}\right]^{-3}-3\left[\ln \left(\frac{C_{0}^{\mathrm{Mg}}}{C_{e}^{\mathrm{Mg}}}\right)-\frac{\Delta G_{s}}{R T_{c}^{*}}\right]^{-2}}\right]^{1 / 3} .
$$

input data from Table VII in combination with other experimental observations. The specific parameters in question are listed in Table I.

Focusing first on the cluster formation, $A_{0}^{\mathrm{c}}$ can be estimated on the basis of the experimental observation that the nucleation rate reaches its peak value at a temperature $T=T_{\mathrm{c}}^{*}$ of about $348 \mathrm{~K}\left(75^{\circ} \mathrm{C}\right) . .^{[41]}$ This
After substitution of the default parameter values listed in Table VII into Eq. [15], an $A_{0}^{c}$-value close to $3 \mathrm{~kJ} / \mathrm{mol}$ is obtained for a typical $\mathrm{Al}-\mathrm{Mg}-\mathrm{Si}$ alloy containing about $0.60 \mathrm{wt}$ pet $\mathrm{Mg}$. This energy barrier is deemed to be representative of heterogeneous nucleation of coherent clusters at trapped vacancies during natural aging. 
When the value of $A_{0}^{c}$ is known, the first constant entering the expression for $j_{0}$ in the nucleation law (see Eq. [2]) can be evaluated from the data reported for the cluster number density in un-deformed Al-Mg-Si alloys. ${ }^{[66]}$ Taking again $N_{\mathrm{v}}=10^{24}$ clusters per $\mathrm{m}^{3}$ as a reasonable estimate for $N_{v 1}$ following complete natural aging, the subsequent back-calculation using Eq. [1] gives a $j_{0}^{c_{1}}$-value close to $5.5 \times 10^{42}$ clusters per $\mathrm{m}^{3} \mathrm{~s}$.

Based on simple calculations, it can be argued that the calibrated $j_{0}^{c_{1}}$-value is about three orders of magnitude higher than expected, assuming that the aluminum matrix vacancy concentration is close to equilibrium. This suggests that the element diffusivity is enhanced by a similar factor due to the presence of excess vacancies in the solution heat treated alloy, thereby allowing $j_{0}$ in the nucleation law to increase beyond its equilibrium value. ${ }^{[4]}$ It follows from Figure 2 that such high concentrations of excess vacancies are readily established during cooling from the solution heat treatment temperature and is thus something that inevitably occurs during thermal processing of Al-Mg-Si alloys. Therefore, their existence provides a plausible explanation for the unphysically high number density of potential nucleation sites that a $j_{0}^{c_{1}}$-value of $5.5 \times 10^{42}$ clusters per $\mathrm{m}^{3} \mathrm{~s}$ otherwise would imply. On the other hand, in a cold-deformed aluminum matrix, the excess vacancies are readily removed by annihilation at dislocations, meaning that the pre-exponential factor $j_{0}$ will drop correspondingly and eventually reach its lower equilibrium value $j_{0}^{c_{2}} \approx 5.5 \cdot 10^{39}$ clusters per $\mathrm{m}^{3}$ s when $\rho=\rho_{\mathrm{c}}$.

A similar procedure, as the one described above, can also be employed to determine the two adjustable parameters $A_{0}^{d}$ and $j_{0}^{d}$ in the new artificial aging nucleation law (see Table I). But, in this case, the nucleation rate will reach its peak value at a much higher temperature $T=T_{d}^{*}$ because the equilibrium solvus of the $\beta^{\prime}$ phase lies significantly above that of the clusters, corresponding to $\Omega_{\mathrm{c}}=0$ in Eq. [5] Assuming that the peak rate is reached at $T_{d}^{*}=628 \mathrm{~K}\left(355^{\circ} \mathrm{C}\right),{ }^{[55]}$ the analogous expression for $A_{0}^{\bar{d}}$ becomes ${ }^{[21]}$.

$$
A_{0}^{d}=\left[\frac{Q_{d}\left(R T_{d}^{*}\right)^{2}}{2\left(Q_{s} / R T_{d}^{*}\right)\left[\ln \left(\frac{C_{0}^{\mathrm{Mg}}}{C_{\mathrm{e}}^{\mathrm{Mg}}}\right)\right]^{-3}-3\left[\ln \left(\frac{C_{0}^{\mathrm{Mg}}}{C_{\mathrm{e}}^{\mathrm{Mg}}}\right)\right]^{-2}}\right]^{1 / 3}
$$

which now is written in its correct form (i.e., with the negative sign placed in front of the second pair of brackets in the denominator).

Based on Eq. [16] and the default parameter values listed in Table VII, a value close to $11 \mathrm{~kJ} / \mathrm{mol}$ is obtained for the $A_{0}^{d}$-parameter when $C_{\mathrm{e}}^{\mathrm{Mg}} \approx 0.60 \mathrm{wt}$ pct. This energy barrier is significantly higher than that calculated for the clusters, which is reasonable in view of the semi-coherent nature of the $\beta^{\prime}$ precipitates.

Then, by using the experimental TEM observation that the $10 \mathrm{pct}$ pre-strained AA6005 base material following artificial aging at $478 \mathrm{~K}\left(205^{\circ} \mathrm{C}\right)$ for $90 \mathrm{~min}-$ utes contains about $6 \times 10^{21} \beta^{\prime}$ particles per $\mathrm{m}^{3},{ }^{[41]}$ the subsequent back-calculation using Eq. [1] gives a corresponding $j_{0}^{d}$-value of about $5.0 \times 10^{33}$ particles per $\mathrm{m}^{3} \mathrm{~s}$.

\section{Determination of Adjustable Parameters in Modified Yield Strength Model}

Finally, in order to make NaMo-Version 2 fully operative, two more constants in the modified yield strength model need to be fixed by calibration by employing experimental data from Series A1. Referring again to Table III, these are the critical radius $r_{c 1}$ defining the hypothetical transition from shearing to bypassing of the clusters by dislocations and the $\beta_{1}$ factor in the expressions for $F_{i}$ and $F_{j}$. The use of the parameters values listed in Tables VII and VIII in combination with inverse-modeling calculations, in which the yield strength model is forced to reproduce two of the test data from Series A1, then give $r_{c 1}=7.0 \times 10^{-9} \mathrm{~m}$ and $\beta_{1}=0.44$.

Table VIII contains a summary of all adjustable parameter values being fixed by calibration to experimental data and implemented in NaMo-Version 2.

\section{EXPERIMENTAL VALIDATION OF NAMO-VERSION 2}

As a starting point, each sub-model in NaMo-Version 2 will be tested against relevant nanostructure and hardness (HV) data being compiled from miscellaneous sources. Subsequently, validation of the numerically integrated models will be carried out using the experimental yield strength data obtained for the hot- and

Table VIII. Summary of Adjustable Parameter Values in NaMo-Version 2 Which Are Fixed by Calibration Using Input Data From Table VII

\begin{tabular}{lll}
\hline Parameter & Value & \multicolumn{1}{c}{ Comments } \\
\hline$A_{0}^{c}(\mathrm{~kJ} / \mathrm{mol})$ & 3 & calculated from Eq. [15] \\
$A_{0}^{d}(\mathrm{~kJ} / \mathrm{mol})$ & 11 & calculated from Eq. [16] \\
$j_{0}^{c_{1}}\left(\# / \mathrm{m}^{3} \mathrm{~s}\right)$ & $5.5 \times 10^{42}$ & calculated using data from Ref. [66] \\
$j_{0}^{c}\left(\# / \mathrm{m}^{3} \mathrm{~s}\right)$ & $5.5 \times 10^{39}$ & equilibrium value of $j_{0}^{c}$ at $\rho=\rho_{c}$ \\
$j_{0}^{d}\left(\# / \mathrm{m}^{3} \mathrm{~s}\right)$ & $5.0 \times 10^{33}$ & calculated using data from Ref. [41] \\
$r_{c 1}(\mathrm{~m})$ & $7.0 \times 10^{-9}$ & calculated using data from Series A1 \\
$\beta_{1}$ & 0.44 & calculated using data from Series A1 \\
\hline
\end{tabular}


Table IX. Overview of Source Data Used in Testing of Different Sub-Models in NaMo-Version 2

\begin{tabular}{|c|c|c|c|c|c|}
\hline \multirow[b]{2}{*}{ Nano-Constituent } & \multicolumn{4}{|c|}{ Experimental and Simulation Conditions } & \multirow[b]{2}{*}{ Source } \\
\hline & Alloy Designation & Type of Treatment & Type of Data Available & Assumed Taylor Factor & \\
\hline Clusters $^{\dagger}$ & $\mathrm{Al}-0.62 \mathrm{Mg}-0.93 \mathrm{Si}$ & NA & $N_{\mathrm{v}}$ and $\bar{r}$ & - & Ref. [66] \\
\hline$\beta^{\prime \prime \dagger \dagger}$ & AA6005 & $\mathrm{AA}$ & $N_{\mathrm{v}}, \bar{r}$ and $\mathrm{HV}$ & 2.7 & Ref. [21] \\
\hline Pre- $\beta^{\prime \prime}$ and $\beta^{\prime \prime \dagger \dagger}$ & AA6082 & $\mathrm{AA}$ & $N_{\mathrm{v}}, \bar{r}$ and $\mathrm{HV}$ & 2.7 & Ref. [17] \\
\hline$\beta^{\prime \prime}$ and $\beta^{\prime \dagger \dagger}$ & AA6060 & $\mathrm{AA}$ and $\mathrm{CD}+\mathrm{AA}$ & $N_{v}, \bar{r}$ and $\mathrm{HV}$ & 2.7 & Ref. [5] \\
\hline
\end{tabular}

cold-rolled AA6005 plate material along with similar literature data being reported for conventional AA6060 and AA6005 extrusions. ${ }^{[56]}$

\section{A. Validation of Different Sub-Models}

The nanostructure data used for validation of the different sub-models in NaMo-Version 2 are taken from well-established sources, where also relevant background information about the experiments can be found. Table IX summarizes the different source data included in the testing program and the experimental \& simulation conditions applied.

\section{Natural aging and artificial aging models}

The individual testing of the natural aging and the artificial aging models is done using the nanostructure data referred to in Table IX for clusters and hardening precipitates, respectively, as the basis for the validation. To enable a direct comparison with outputs from NaMo-Version 2, the reported volumes of the needleand rod-shaped precipitates are taken identical to those of corresponding spherical particles of mean radius $\bar{r}$.

Figure 5(a) shows a plot of predicted vs. measured particle number density, covering a range in $N_{\mathrm{v}}$ of more than two decades. Figure 5(b) shows a similar plot of predicted $v s$ measured particle radius. In both cases, the data points are seen to cluster quite evenly around the $45 \mathrm{deg}$ line defining the expected (mean) values in the graphs, although the overall spread of the data is admittedly large. Assuming that the observed spread is normally distributed around this mean, a 68 pct confidence interval of \pm 105 and \pm 44 pct is calculated for the population representing the particle number density $N_{\mathrm{v}}$ and the mean particle radius $\bar{r}$, respectively. This confidence interval is equal to $\pm \mathrm{SD}$ (i.e., the standard deviation of the distribution).

\section{Cold deformation and static recovery models}

The experimental data reproduced in Figure 6 for the dislocation density $\rho$ refer to experiments carried out on a 6005 type of alloy. ${ }^{[56]}$ After solution heat treatment, the alloy was first naturally aged for three days, then subjected to 10 pct cold deformation, and subsequently stored for another four days at RT before it was

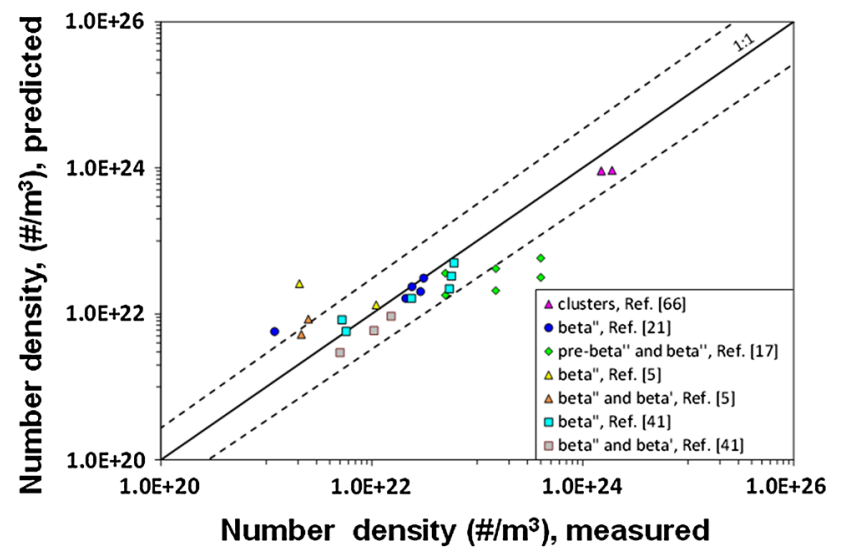

(a)

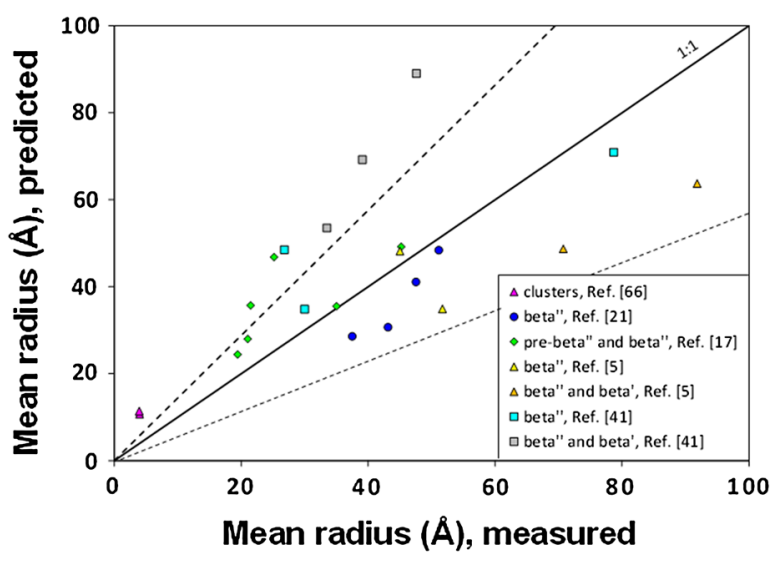

(b)

Fig. 5-Validation of natural aging and artificial aging models in NaMo-Version 2 against the experimental nanostructure data referred to in Table IX: $(a)$ scatter plot of predicted vs. measured particle number density, $(b)$ scatter plot of predicted vs measured particle radius. Broken lines in the graphs represent the 68 pct confidence interval.

artificially aged at $458 \mathrm{~K}\left(185^{\circ} \mathrm{C}\right)$ for different holding times. Note that each of the four data points used to validate the models represents the average of 10 to 15 independent measurements of $\rho$ being performed at various locations across the thin foil. The error bars indicated show the standard deviation of these. 


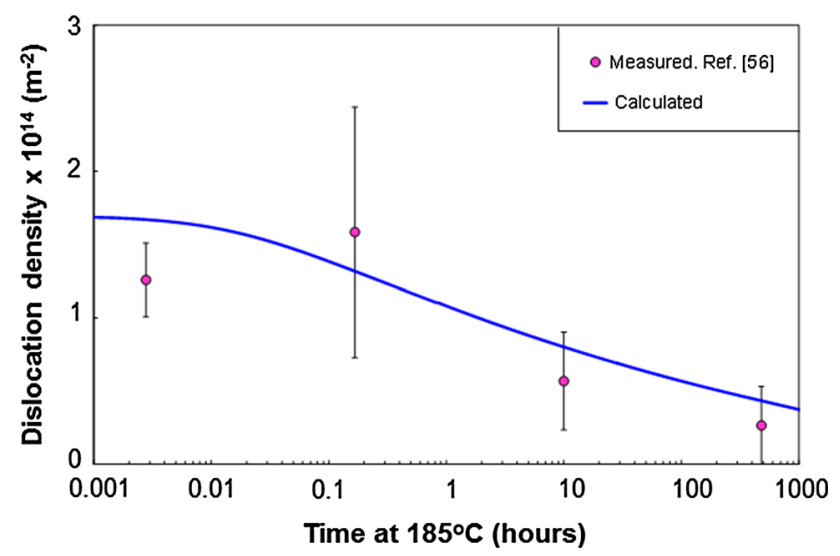

Fig. 6-Validation of cold deformation and static recovery models in NaMo-Version 2 based on a comparison with measured values for the dislocation density. The error bars included represent the standard deviation of 10 to 15 independent measurements. The experimental conditions which relate to these source data are summarized in Table IX and further elaborated in the text.

A comparison with the simulation results being included in Figure 6 reveals that the initial increase in the dislocation density caused by the cold deformation is adequately accounted for by the cold deformation model. At the same time, the static recovery model correctly captures the subsequent decrease in $\rho$ during artificial aging. This is encouraging, because the dislocation density is an important internal variable in NaMo-Version 2 affecting both the precipitation kinetics and the yield strength.

\section{Yield strength model}

Since information about either hardness or yield strength also is available for the alloys included in the previous testing of the natural aging and artificial aging models, it is possible to obtain an independent check of the predictive power of the yield strength model as well. As a starting point for this validation, the original data in Figure 5 for the particle number density and mean radius are restored and inserted back into Eq. [14] to calculate the pertinent $\sigma_{\mathrm{p}}$-contribution from clusters and hardening precipitates, respectively, to the overall yield strength. Subsequently, the same datasets for $N_{\mathrm{v}}$ and $\bar{r}$ are used to compute the resulting particle volume fractions $f$, taking

$$
f=\frac{4}{3} \pi \bar{r}^{3} N_{\mathrm{v}}
$$

Then, based on these $f$-values and knowledge of the nominal alloy compositions, the content of $\mathrm{Mg}$ and $\mathrm{Si}$ in solid solution can be estimated via the thermodynamic model and inserted back into Eq. [11] to obtain the corresponding $\sigma_{\mathrm{ss}}$-contributions. Finally, by inserting the relevant combinations of $\sigma_{\mathrm{p}}$ and $\sigma_{\mathrm{ss}}$ into Eq. [10] along with the Taylor factors listed in Table IX, the yield strength $\sigma_{\mathrm{y}}$ can be calculated and compared with measurements. The results are summarized in Figures 7(a) and (b). It follows from the figure captions

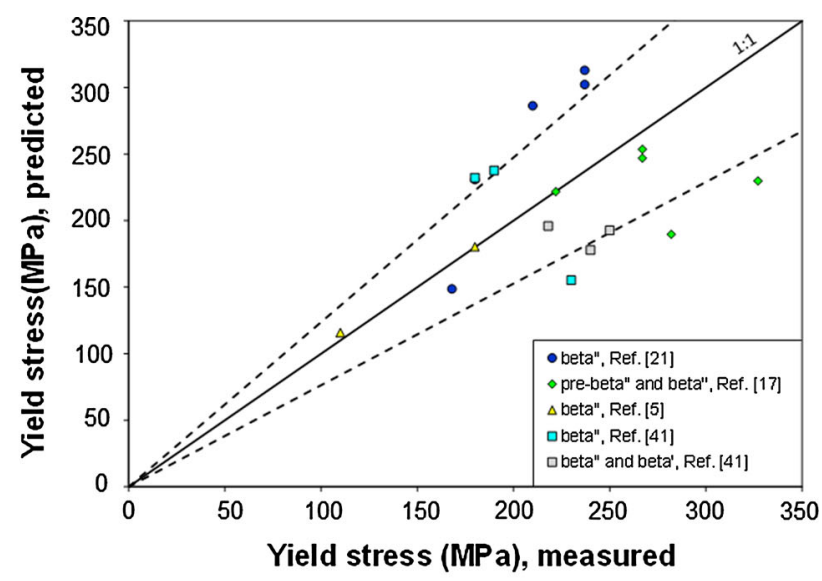

(a)

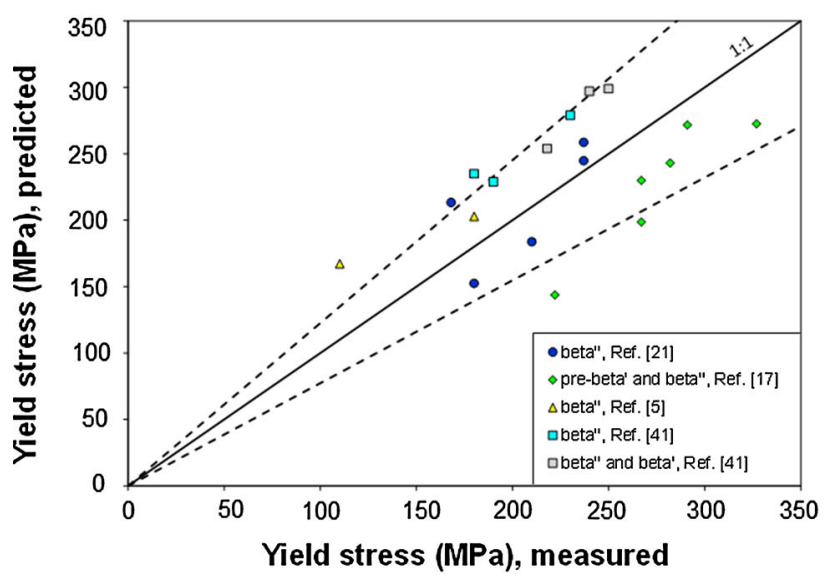

(b)

Fig. 7-Validation of yield strength model in NaMo-Version 2 against the experimental hardness and yield strength data referred to in Table IX: $(a)$ scatter plot of predicted $v s$. measured yield strength using experimental input values for $N_{\mathrm{v}}$ and $r,(b)$ scatter plot of predicted vs. measured yield strength using simulated input values for $N_{\mathrm{v}}$ and $r$. Broken lines in the graphs represent the 68 pct confidence interval.

that the main difference between these two scatter plots is that the former is constructed on the basis of experimental input values for $N_{\mathrm{v}}$ and $\bar{r}$, whereas the latter scatter plot is based on simulated values for the same parameters using outputs from NaMo-Version 2.

Note that in cases where only experimental hardness data are available for comparison, the following wellestablished relationship is used to convert from Vickers hardness $(\mathrm{HV})$ to yield strength ${ }^{[21,29]}$ :

$$
\sigma_{\mathrm{y}}=3.0 \mathrm{HV}-48.1
$$

A closer inspection of Figure 7(a) and (b) reveals that the overall predictive power of the yield strength model is not sensitive to the type of input data used in the calculations, i.e., whether they are based on measured values for $N_{\mathrm{v}}$ and $\bar{r}$ or obtained through simulations of the same parameters using NaMo-Version 2. This follows from a comparison of the calculated $68 \mathrm{pct}$ 
confidence intervals for the two populations (equal to 23.7 and 22.6 pct, respectively). Still, they differ from each other in the sense that the location of the data points within the first scatter plot is different from the location of the same data points within the other one. Thus, it appears that the additional use of NaMo-Version 2 to generate the required input values for $N_{\mathrm{v}}$ and $\bar{r}$ just contributes to an internal regrouping the yield strength data in stress space without compromising the accuracy of the predictions. This suggests that the largest source of uncertainty is actually the yield strength model itself and not the underlying nanostructure models.

\section{B. Validation of Numerically Integrated Models}

The next step in the validation process is to test the numerically integrated models against experimental yield strength data for different base materials under conditions where all of the NaMo sub-models come into play.

\section{Yield strength data for hot and cold-rolled AA6005} plate material

In Figure 8(a), the results from Series A1 through A7 are plotted versus total storage time at RT (i.e., $t_{1}+t_{2}$ ) and compared with calculations using NaMo-Version 2. As can be seen from the figure, the combined workhardening and natural aging model adequately captures the sudden increase in the yield strength caused by the imposed cold deformation at both strain levels as well as the resulting aging response during prolonged roomtemperature storage. Moreover, it is evident from the statistical analyses of the same results in Figure 8(b) that the yield strength data tend to spread evenly on each side of the $45 \mathrm{deg}$ line defining the expected (mean) values in the plot. Assuming that the observed spread of the data is normally distributed around this mean, a 68 pct confidence interval of \pm 12.7 pct is obtained for the entire population (equal to $\pm \mathrm{SD}$ ).

Figure 9(a) shows the effect of prolonged room-temperature storage on the subsequent yield strength evolution during artificial aging at $458 \mathrm{~K}\left(185^{\circ} \mathrm{C}\right)$ for the same alloy. For clarity, only the results pertaining to Series B1 and B5 in Table VI are included in the graph. As expected, prolonged room-temperature storage is seen to have a significant effect on the resulting artificial aging response. For example, in the beginning of the process, before the precipitation of the $\beta^{\prime \prime}$ particles has started, the yield stress will be higher after long storage times compared with short ones, as shown by the two crossing hardening curves in Figure 9(a). This is because the number density of clusters increases with increasing RT storage times. On the other hand, a high number density of clusters implies that the supersaturation will be lower at the onset of the aging process. This reduces the nucleation rate of the $\beta^{\prime \prime}$ particles during artificial aging, which, in turn, lowers the RT yield stress.

Figure 9(b) shows corresponding plots of the yield strength evolution during artificial aging at $458 \mathrm{~K}$ $\left(185^{\circ} \mathrm{C}\right)$ after 0,2 , and 10 pct cold deformation, respectively, in combination with prolonged room-temperature

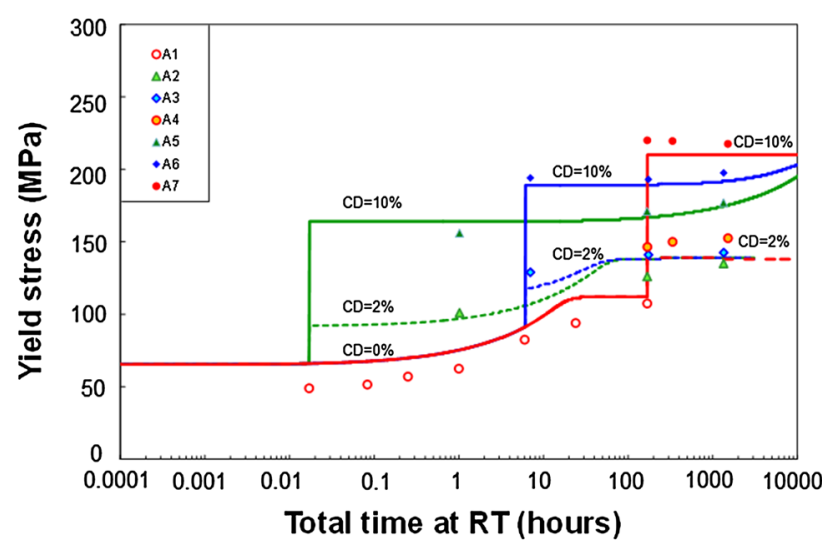

(a)

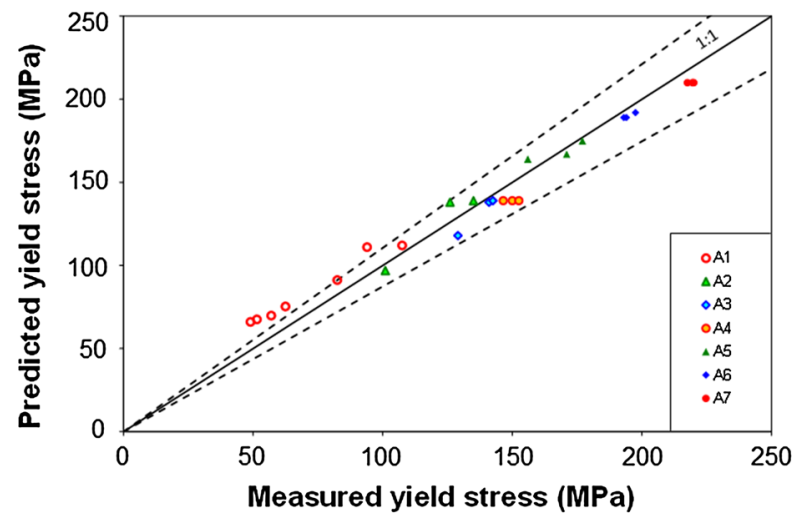

(b)

Fig. 8- Graphical representations of all simulation and test results pertaining to Series A (see Table V for details): $(a)$ combined effect of cold deformation and prolonged room-temperature storage on the resulting yield strength evolution during natural aging, $(b)$ evaluation of the predictive power of NaMo-Version 2, based on a statistical analysis of the same test results. In this plot, the broken lines represent the 68 pet confidence interval.

storage, using data from Series B2, B7, and B11. Since the contribution from cold deformation and dislocation hardening is most predominant early in the process, the initial yield stress will be highest for the 10 pct prestrained material. Moreover, due to their open core structure, the dislocations generated will also speed up the intrinsic precipitation reactions by acting as highdiffusivity paths for solute atoms in the aluminum matrix. At the same time, the dislocations may become detrimental to strength in cases where they alter the precipitation reaction sequence during artificial aging. This occurs if the static recovery kinetics are too slow to reduce the number density $\rho$ below the critical value $\rho_{\mathrm{c}}$ on heating to the artificial aging temperature $T_{\mathrm{AA}}$. For example, it follows from Figure 4 that the $\beta^{\prime \prime}$ evolution will be suppressed in the 10 pct pre-strained material because of competitive nucleation of $\beta^{\prime}$ particles at dislocations, while both types of hardening phases may form when the pre-straining is 2 pct. This explains why the observed peak strength in Figure 9(b) starts to drop off at 10 pct plastic deformation, although the contribution from dislocation hardening to the total yield stress in this case is highest. 


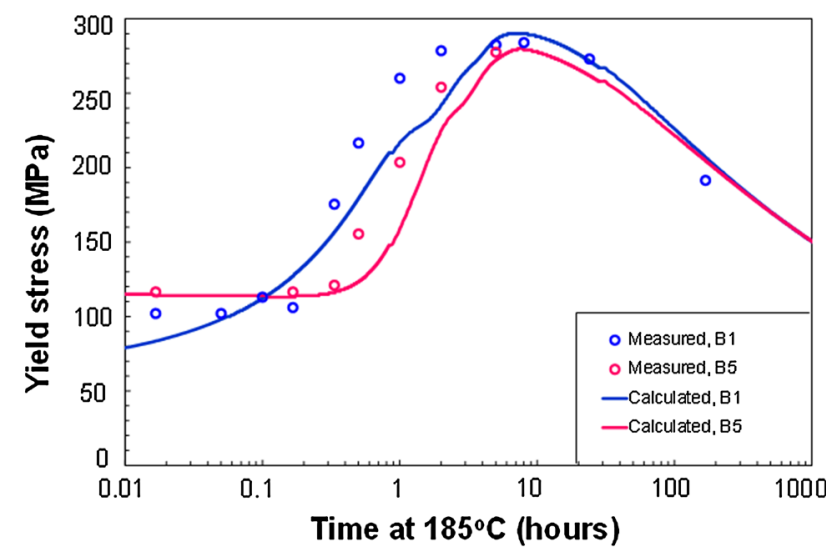

(a)

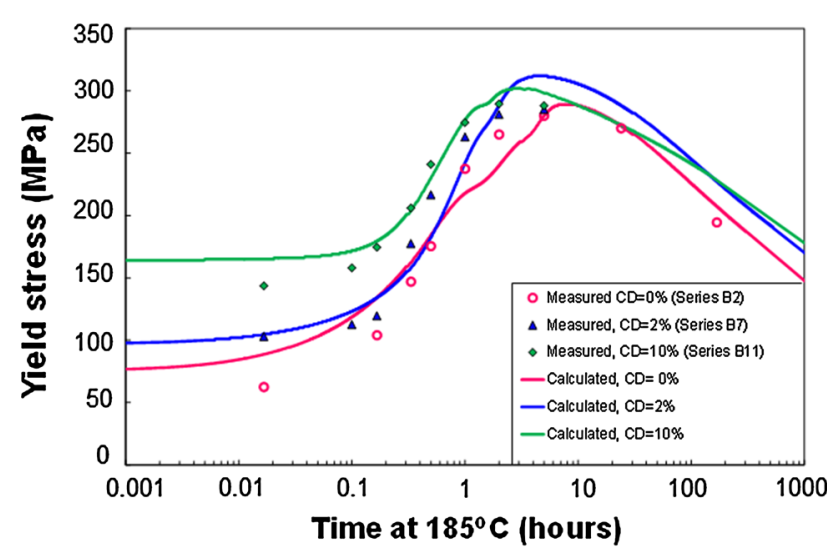

(b)

Fig. 9- Graphical representations of some simulation and test results pertaining to Series B (see Table VI for details): $(a)$ effect of prolonged room-temperature storage on the resulting yield strength evolution during artificial aging, $(b)$ corresponding response of the same alloy to artificial aging following cold deformation and prolonged room-temperature storage.

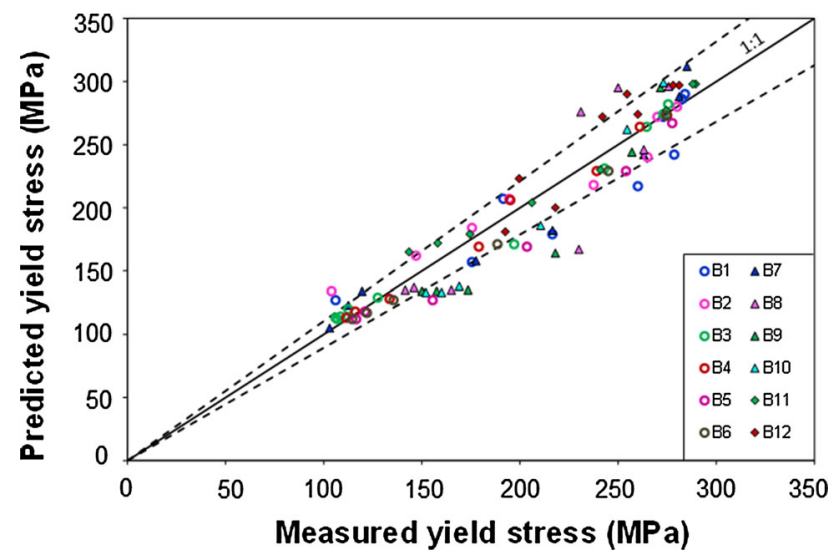

Fig. 10-Evaluation of the predictive power of NaMo-Version 2, based on a statistical analysis of all test results pertaining to Series B (see Table VI for details). In this scatter plot the broken lines represent the 68 pct confidence interval.

Note that the observed wiggles or kinks in the predicted strength curves in Figure 9 (as well as in later plots) are not numerical artifacts. One possibility is that

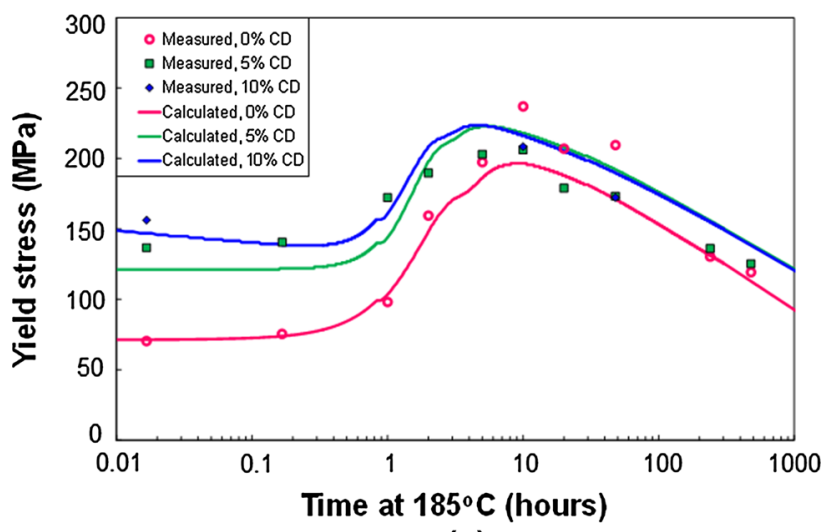

(a)

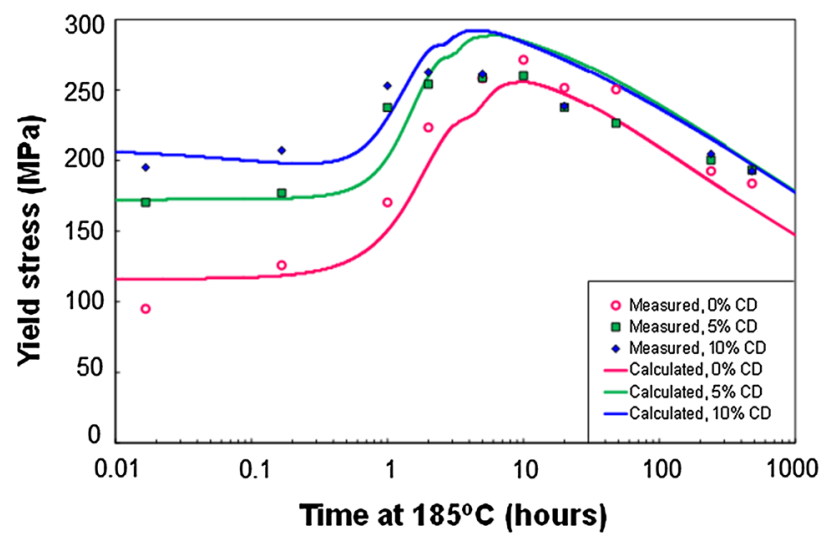

(b)

Fig. 11- Graphical representations of some simulation and test results pertaining to two conventional $\mathrm{Al}-\mathrm{Mg}-\mathrm{Si}$ extrusions: (a) combined effect of cold deformation and prolonged room-temperature storage on the resulting yield strength evolution during artificial aging of AA6060, (b) corresponding artificial aging response of AA6005 for the same combinations of cold deformation and RT storage times as above (i.e., $t_{1}=3$ days and $t_{2}=4$ days).

they originate from the assumption of linear additive strength contributions in NaMo-Version 2, which under given circumstances may lead to fluctuations in $\sigma_{\mathrm{y}}$ when different strengthening mechanisms come into play at the same time. Alternatively, they could be real with a mechanistic origin. The latter conclusion is supported by the fact that wiggles or kinks also appear in experimental artificial aging curves for Al-Mg-Si alloys which are based on hardness measurement. ${ }^{[17]}$

Similarly, Figure 10 contains a compilation of all test results for Series B. This figure shows a plot of calculated RT yield stress vs measured yield stress for the different tensile tests referred to in Table VI. Again, the data points tend to spread evenly on each side of the $45 \mathrm{deg}$ line defining the expected (mean) values in the graph. Then, by assuming that the spread is normally distributed around this mean, a 68 pct confidence interval of \pm 10.6 pct is obtained for the entire population (equal to $\pm \mathrm{SD}$ ). 


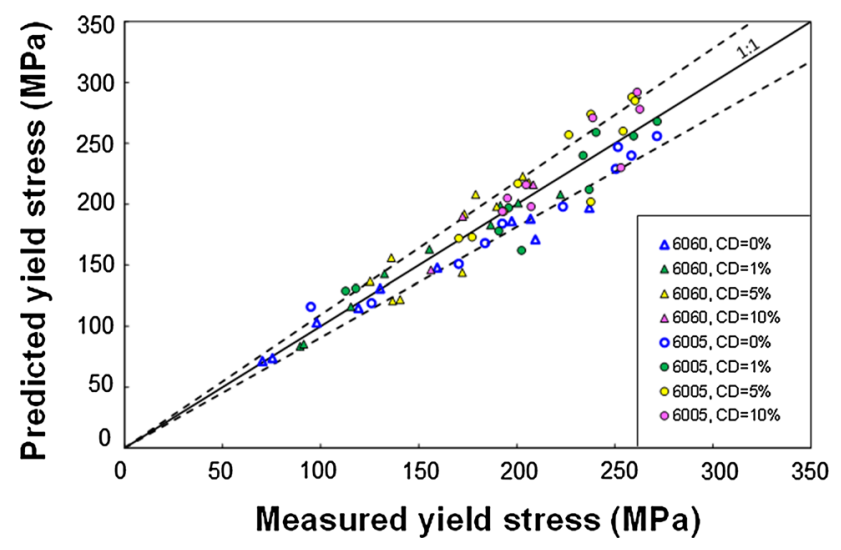

Fig. 12-Evaluation of the predictive power of NaMo-Version 2, based on a statistical analysis of all test results pertaining to the two AA6060 and AA6005 extrusions reported by Furu et al. ${ }^{[56]}$ In this scatter plot, the broken lines represent the 68 pct confidence interval.

\section{Yield strength data for conventional AA6060 and AA6005 extrusions}

In Figure 11, the predictive power of NaMo-Version 2 is tested against independent yield strength data being reported for conventional Al-Mg-Si extrusions. ${ }^{[56]}$ Figure 11(a) shows plots of the yield strength evolution during artificial aging of a 5-mm-thick AA6060 extruded profile being subjected to both cold deformation and prolonged room-temperature storage prior to heat treatment. Figure 11(b) contains similar results for a 5-mmthick profile of the AA6005 type. In NaMo-Version 2, the recrystallized microstructure of AA6060 is allowed for by taking the Taylor factor $M$ in the simulations equal to 2.7. ${ }^{[7]}$ As expected, the overall artificial aging response of the extruded AA6060 and AA6005 profiles to cold deformation and prolonged room-temperature storage is similar to that observed for the hot- and cold-rolled AA6005 plate material in Figure 9(b). Still, both the absolute strength level as well as the time to reach the peak strength are seen to vary significantly between the alloys. This is because the strength evolution during artificial aging does not just depend on chemistry but is also sensitive to variations in the starting microstructure, the degree of cold deformation, and the applied RT storage time, as determined by the thermomechanical history of the alloys. Apparently, all these factors are adequately accounted for by NaMo-Version 2.

Finally, Figure 12 shows a plot of predicted RT yield stress $v s$. measured yield stress for the same alloys, based on a compilation of all test results reported in Reference 56. For these extrusions, most of the data points seem to fall within a scatter-band of \pm 9.3 pct. This calculated band width, which is equal to the 68 pct confidence interval for the entire population, is slightly smaller than that observed in Figure 10 for the AA6005 plate material.

\section{CASE STUDY: FORMING AND PAINT-BAKE HARDENING OF AA6005}

In the present case study, NaMo-Version 2 is used to simulate the microstructure and strength evolution in naturally aged and cold-deformed AA6005 sheets being subjected to renewed RT storage prior to paint-bake hardening.

\section{A. Problem Description}

The schematic process chain diagram in Figure 2 provides a good starting point for clarifying the problem. In the case study, the storage time $t_{1}$ represents the elapsed time from solution heat treatment (as done by the aluminum producer) to the start of the cold forming operation, which is performed by the body panel manufacturer. Then the body panel is stored for a certain period of time $t_{2}$ at RT before painting and paint-bake hardening. In a real production situation, both $t_{1}$ and $t_{2}$ can vary within wide limits. At the same time, the applied paint-bake hardening thermal cycle is fixed to ensure optimal paint properties in the final product. This means that a possible strength reduction, being triggered by the cluster formation and the use of cold deformation earlier in the process, cannot readily be compensated by a change in the artificial aging program.

\section{B. Simulation Results}

The simulations are carried out at $T_{\mathrm{AA}}=458 \mathrm{~K}$ $\left(185^{\circ} \mathrm{C}\right)$ and $t_{3}=30$ minutes. This heat treatment schedule is deemed to be representative of paint-bake hardening of aluminum body panels. In the case study the effect of three different deformation levels is examined, i.e., 2, 5 and 10 pct, respectively. Each of them corresponds to a specific location across a curved section of the panel, as illustrated in Figure 13(a).

The results from the simulations are summarized in Figure 13(b). As expected, the final yield strength of the body panel is seen to depend both on the storage time $t_{1}$ between solution heat treatment and cold deformation, the applied plastic strain during the forming operation as well as the subsequent storage time $t_{2}$ prior to paint-bake hardening. For example, in a real production situation, where neither $t_{1}$ nor $t_{2}$ are fixed, Figure 13(b) predicts that the strength level may vary as much as $70 \mathrm{MPa}$ across a curved section of the body panel, unless unrealistically short storage times are used. At the same time, the absolute yield strength in the low-strain regions can drop as low as $140 \mathrm{MPa}$.

Instead of applying traditional pre-baking as a means to stabilize the alloy following solution heat treatment, an alternative method would be to cold-deform the alloy before it is sent to the body panel manufacturer. This is because NaMo-Version 2 predicts that cold deformation will indirectly increase the solute level in the naturally aged material by restricting the cluster formation through a reduction in the nucleation rate. During subsequent paint-bake hardening, more solute will lead to enhanced precipitation of hardening precipitates in the alloy. As indicated in Figure 13(b), a pre-straining of about 5 pct should remove most of its sensitivity to prolonged room-temperature storage if the deformation is applied immediately after the solution heat treatment. This, in turn, can raise the minimum yield strength level 


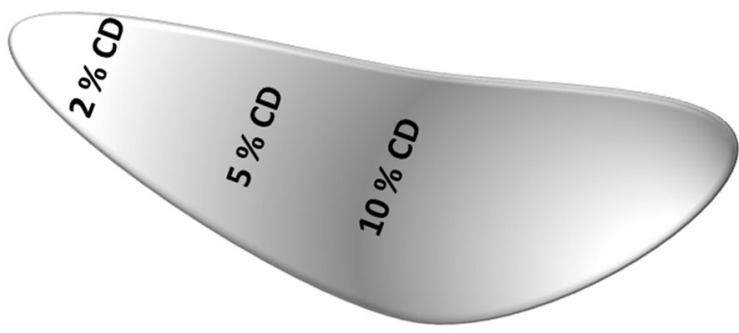

(a)

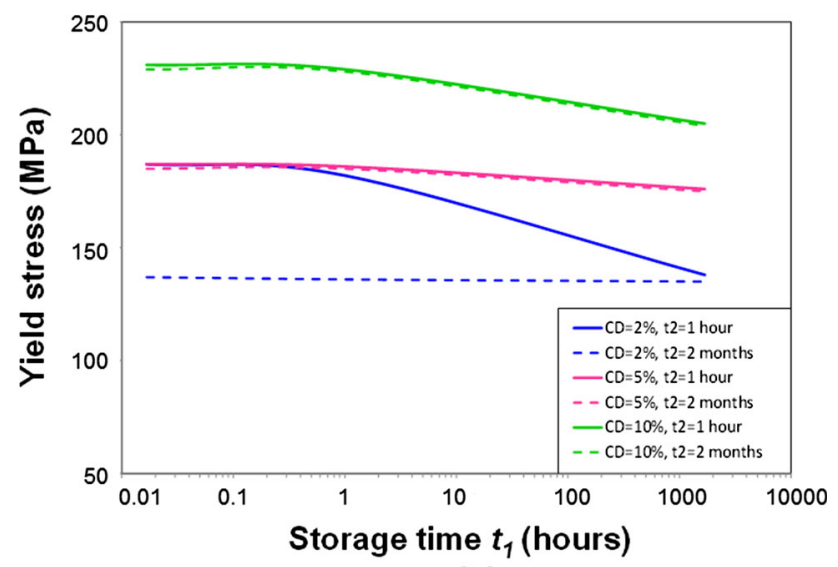

(b)

Fig. 13 - Case study on cold forming and paint-bake hardening of AA6005 sheets: $(a)$ sketch of a curved section of the body panel, $(b)$ combined effects of prolonged room-temperature storage and cold deformation on the resulting yield strength of the body panel following paint-bake hardening.

in the final product from 140 to, say, $180 \mathrm{MPa}$, without a considerable increase in the production costs.

\section{CONCLUSIONS}

The main conclusions to be drawn from the development and testing of NaMo-Version 2 can be summarized as follows:

In general, simulation of thermomechanical processing of Al-Mg-Si alloys involving cold-working operations like sheet forming and stretch bending in combination with heat treatment and welding requires the use of an age-hardening model which takes into account the combined effect of cold deformation and prolonged room-temperature storage on the subsequent artificial aging response. To enable this, the original physical framework of NaMo-Version 1 has been revived and used as a basis for the extension.

As a starting point, the important reactions contributing to the nanostructure evolution during natural aging, cold deformation, and artificial aging are first identified and then implemented, either in the existing NaMo sub-models, or in new ones. Subsequently, they are linked together in a manner that enforces solute partitioning and competition between the different nano-constituents which form during thermomechanical processing (e.g., clusters, $\beta^{\prime \prime}$ and $\beta^{\prime}$ ) using the Kampmann-Wagner formalism.
Because of the large number of strengthening mechanisms involved, the original framework for calculating the macroscopic yield strength has been modified to allow for the contributions from precipitation hardening, solid solution hardening, and strain hardening within the same model. Also the effect of crystallographic texture on the base metal mechanical properties is accounted for in the new yield strength model.

In Al-Mg-Si alloys, the particle obstacle strength will be shape dependent, which follows from an in-depth mathematical analysis of the underlying particle-dislocation interactions. In practice, however, the pertinent difference in the obstacle strength between rod-shaped and spherical particles can readily be compensated for by calibrating the yield strength model against experimental data. Since this is a standard operating procedure in all industrial process modeling, the particle shape correction is not incorporated in NaMo-Version 2.

Because NaMo-Version 2 contains many different input parameters which must be fixed before a prediction can be made, a special methodology (or calibration strategy) has also been worked out in parallel with the on-going model development in order to deal with this problem. The main idea behind the calibration strategy is that the parameter values serving as defaults in the program should primarily be settled based on what is already known in the scientific literature. If such source data are not available, they must alternatively be obtained by calibrating the constitutive equations against experimental data.

Following calibration, the different sub-models in NaMo-Version 2 are first tested against dedicated nanostructure data being compiled from miscellaneous sources. Then the outputs from the numerically integrated models are validated using experimental yield strength data obtained from tensile testing of both rolled sheet material and extruded profiles.

The results show that cold deformation in combination with natural aging have a clear negative effect on the yield strength. This is because the dislocations generated tend to suppress the formation of clusters and $\beta^{\prime \prime}$ precipitates in the aluminum matrix by virtue of their ability to act as sinks for excess vacancies and solute atoms. Instead, direct nucleation of $\beta^{\prime}$ particles at dislocations is boosted.

Based on the results obtained, it is concluded that NaMo-Version 2 provides a powerful tool for predicting the response of $\mathrm{Al}-\mathrm{Mg}-\mathrm{Si}$ alloys to thermomechanical processing, and an illustration of this is provided in a separate case study toward the end of the article.

\section{ACKNOWLEDGMENTS}

The authors acknowledge the financial support provided by Hydro Aluminium and the Norwegian Research Council through SFI CASA - Centre for Research-Based Innovation at the Norwegian University of Science and Technology, Trondheim, Norway 
and SFI MANUFACTURING - Centre for ResearchBased Innovation at SINTEF Raufoss Manufacturing $\&$ the Norwegian University of Science and Technology, Raufoss, Norway.

\section{OPEN ACCESS}

This article is distributed under the terms of the Creative Commons Attribution 4.0 International License (http://creativecommons.org/licenses/by/4.0/), which permits unrestricted use, distribution, and reproduction in any medium, provided you give appropriate credit to the original author(s) and the source, provide a link to the Creative Commons license, and indicate if changes were made.

\section{APPENDIX A}

\begin{tabular}{ll}
\multicolumn{2}{c}{ Abbreviations } \\
AA & Artificial aging \\
CD & Cold deformation \\
DSC & Differential scanning calorimetry \\
HV & Hardness based on the Vickers test \\
NA & Natural aging \\
NaMo & Nanostructure model \\
PFZ & Precipitate-free zone \\
PWHT & Post-weld heat treatment \\
RT & Room temperature \\
SD & Standard deviation of a normal distribution \\
SHT & Solution heat treatment \\
SR & Static recovery \\
sS & Solid solution \\
TD & Thermodynamic \\
TEM & Transmission electron microscopy \\
TH & Thermal \\
W & Welding \\
WH & Work hardening \\
YS & Yield strength
\end{tabular}

\footnotetext{
Symbols and Units

$a_{\mathrm{c}} \quad$ Cross-sectional area of pipes in expression for $D_{\text {eff }}\left(\mathrm{m}^{2}\right)$
}

$A_{0}^{\mathrm{c}} \quad$ Parameter related to the energy barrier for heterogeneous nucleation of clusters in $\mathrm{Al}$ matrix $(\mathrm{J} / \mathrm{mol})$

$A_{0}^{\mathrm{d}} \quad$ Parameter related to the energy barrier for heterogeneous nucleation of $\beta^{\prime}$ particles at dislocations $(\mathrm{J} / \mathrm{mol})$

$A_{0}^{m} \quad$ Parameter related to the energy barrier for heterogeneous nucleation of $\beta^{\prime \prime}$ particles in $\mathrm{Al}$ matrix $(\mathrm{J} / \mathrm{mol})$

$b \quad$ Magnitude of Burgers vector (m)

$C \quad$ Concentration (wt pct)

$\bar{C} \quad$ Mean solute concentration in matrix (wt pct)

$C_{\mathrm{e}}^{\mathrm{Mg}} \quad$ Equilibrium concentration of magnesium at cluster/matrix or particle/matrix interface (wt pct)
$C_{\mathrm{i}}^{\mathrm{Mg}} \quad$ Magnesium concentration at cluster/matrix or particle/matrix interface during evolution (wt pct)

$C_{0}^{\mathrm{Fe}} \quad$ Nominal concentration of iron in alloy (wt pct)

$C_{0}^{\mathrm{Mg}} \quad$ Nominal concentration of magnesium in alloy (wt pct)

$C_{0}^{\mathrm{Mn}} \quad$ Nominal concentration of manganese in alloy (wt pet)

$C_{0}^{\mathrm{Si}} \quad$ Nominal concentration of silicon in alloy (wt pct)

$C_{k} \quad$ Concentration of specific element $k$ in expression for $\sigma_{\mathrm{ss}}$ (wt pct)

$C_{\mathrm{p}}^{\mathrm{Mg}} \quad$ Concentration of magnesium inside clusters or particles (wt pct)

$C_{s} \quad$ Pre-exponential term in expression for $c_{\mathrm{e}}^{\mathrm{mg}}(\mathrm{wt}$ pct)

$C_{\mathrm{ss}}^{\mathrm{Mn}} \quad$ Concentration of manganese in solid solution (wt pct)

$C_{\mathrm{ss}}^{\mathrm{Si}} \quad$ Concentration of silicon in solid solution (wt pct)

$D^{\mathrm{Mg}} \quad$ Bulk diffusion coefficient of magnesium in aluminum $\left(\mathrm{m}^{2} / \mathrm{s}\right)$

$D_{0}^{\mathrm{Mg}} \quad$ Pre-exponential term in expression for $D^{\mathrm{Mg}}$ $\left(\mathrm{m}^{2} / \mathrm{s}\right)$

$D_{\mathrm{c}}^{\mathrm{Mg}} \quad$ Core diffusion coefficient for magnesium in aluminum $\left(\mathrm{m}^{2} / \mathrm{s}\right)$

$D_{C_{0}}^{\mathrm{Mg}} \quad$ Pre-exponential term in expression for $D_{\mathrm{c}}^{\mathrm{Mg}}$ $\left(\mathrm{m}^{2} / \mathrm{s}\right)$

$D_{\text {eff }}^{\mathrm{Mg}} \quad$ Effective diffusion coefficient for magnesium in aluminum $\left(\mathrm{m}^{2} / \mathrm{s}\right)$

$f \quad$ Total volume fraction of clusters and hardening precipitates

$f_{\mathrm{r}} \quad$ Volume fraction of rod-shaped particles

$f_{\mathrm{s}} \quad$ Volume fraction of monodispersive spherical particles

$\bar{F} \quad$ Mean interaction force between particles and dislocations $(\mathrm{N})$

$\overline{F_{1}} \quad$ Mean interaction force between clusters and dislocations $(\mathrm{N})$

$\overline{F_{2}} \quad$ Mean interaction force between hardening $\beta^{\prime \prime}$ and $\beta^{\prime}$ precipitates and dislocations $(\mathrm{N})$

$F_{i} \quad$ Mean interaction force between clusters and dislocations within size class $r_{i}(\mathrm{~N})$

$F_{j} \quad$ Mean interaction force between hardening $\beta^{\prime \prime}$ and $\beta^{\prime}$ precipitates and dislocations within size class $r_{j}(\mathrm{~N})$

$\overline{F_{r}} \quad$ Mean interaction force between rod-shaped particles and dislocations $(\mathrm{N})$

$\overline{F_{s}} \quad$ Mean interaction force between monodispersive spherical particles and dislocations $(\mathrm{N})$

$G \quad$ Shear modulus (N/m $/ \mathrm{m}^{2}$ or $\left.\mathrm{GPa}\right)$

$\Delta G^{*} \quad$ Energy barrier for heterogeneous nucleation $(\mathrm{J} / \mathrm{mol})$

$\Delta G_{\mathrm{s}} \quad$ Misfit strain energy term in expression for $\Delta G^{*}(\mathrm{~J} / \mathrm{mol})$

$j \quad$ Nucleation rate $\left(\# / \mathrm{m}^{3} \mathrm{~s}\right)$

$j_{0} \quad$ pre-exponential factor in general expression for $j\left(\# / \mathrm{m}^{3} \mathrm{~s}\right)$

$j_{0}^{c_{1}}, j_{0}^{c_{2}}$ Pre-exponential factors in NA nucleation law for cluster formation $\left(\# / \mathrm{m}^{3} \mathrm{~s}\right)$ 
Pre-exponential factor in AA nucleation law for $\beta^{\prime}$ formation at dislocations $\left(\# / \mathrm{m}^{3} \mathrm{~s}\right)$

$j_{0}^{m} \quad$ Pre-exponential factor in AA nucleation law for $\beta^{\prime \prime}$ formation in Al matrix ( $\left.\# / \mathrm{m}^{3} \mathrm{~s}\right)$

$k_{1} \quad$ Parameter related to statistical storage of dislocations $\left(\mathrm{m}^{-1}\right)$

$k_{2} \quad$ Parameter related to dynamic recovery of dislocations

$k_{3} \quad$ Parameter determining the rate of dislocation annihilation in SR model $(\mathrm{m} / \mathrm{s})$

$k_{4} \quad$ Energy term determining the activation length of dislocations in SR model $(\mathrm{Jm} / \mathrm{mol})$

$k_{k} \quad$ Scaling factor in expression for $\sigma_{\mathrm{ss}}\left(\mathrm{N} / \mathrm{m}^{2}\right.$ $\mathrm{wt} \mathrm{pct}^{2 / 3}$ or $\mathrm{MPa} / \mathrm{wt} \mathrm{pet}^{2 / 3}$ )

$\ell \quad$ Mean planar spacing between particles in the slip plane along the bending dislocation $(\mathrm{m})$

$\ell_{1} \quad$ Mean planar spacing between clusters in the slip plane along the bending dislocation $(\mathrm{m})$

$\ell_{2} \quad$ Mean planar spacing between hardening $\beta^{\prime \prime}$ and $\beta^{\prime}$ precipitates in the slip plane along the bending dislocation $(\mathrm{m})$

$\ell_{\mathrm{r}} \quad$ Mean planar spacing between rod-shaped particles in the slip plane along the bending dislocation $(\mathrm{m})$

$\ell_{\mathrm{s}} \quad$ Mean planar spacing between monodispersive spherical particles in the slip plane along the bending dislocation $(\mathrm{m})$

$L_{\mathrm{r}} \quad$ Length of rod-shaped particles (m)

$m$ exponent defining the obstacle strength

$M \quad$ Taylor factor

$M_{\mathrm{r}} \quad$ Reference value for the Taylor factor

$M_{0} \quad$ Pre-exponential term in expression for the

cluster interface mobility (m/s wt pct)

$N_{\mathrm{a}}^{\mathrm{r}} \quad$ Number of rod-shaped particles per unit area of the slip planes $\left(\# / \mathrm{m}^{3}\right)$

$N_{\mathrm{a}}^{\mathrm{s}} \quad$ Number of monodispersive spherical particles per unit area $\left(\# / \mathrm{m}^{3}\right)$

$N_{i} \quad$ Number of clusters per unit volume within size class $r_{i}\left(\# / \mathrm{m}^{3}\right)$

$N_{j} \quad$ Number of hardening $\beta^{\prime \prime}$ and $\beta^{\prime}$ precipitates per unit volume within size class $r_{j}\left(\# / \mathrm{m}^{3}\right)$

$N_{\mathrm{v}} \quad$ Particle number density $\left(\# / \mathrm{m}^{3}\right)$

$N_{\mathrm{v} 1} \quad$ Total number of clusters per unit volume $\left(\# / \mathrm{m}^{3}\right)$

$N_{\mathrm{v} 2} \quad$ Total number of hardening $\beta^{\prime \prime}$ and $\beta^{\prime}$ precipitates per unit volume $\left(\# / \mathrm{m}^{3}\right)$

$N_{\mathrm{v}}^{\mathrm{r}} \quad$ Number of rod-shaped particles per unit volume $\left(\# / \mathrm{m}^{3}\right)$

$N_{\mathrm{v}}^{\mathrm{s}} \quad$ Number of monodispersive spherical particles per unit volume $\left(\# / \mathrm{m}^{3}\right)$

$Q_{\text {c }} \quad$ Activation energy for core diffusion of magnesium in aluminum $(\mathrm{J} / \mathrm{mol})$

$Q_{\mathrm{d}} \quad$ Activation energy for bulk diffusion of magnesium in aluminum or diffusion of magnesium across the cluster/matrix interface $(\mathrm{J} / \mathrm{mol})$

$Q_{\text {s }} \quad$ Apparent solvus boundary enthalpy for stable and metastable phases including clusters $(\mathrm{J} / \mathrm{mol})$

$r \quad$ Particle or cluster radius (m)

$\bar{r} \quad$ Mean particle radius $(\mathrm{m})$

$\overline{r_{1}} \quad$ Mean radius of clusters $(\mathrm{m})$ $\overline{r_{2}} \quad$ Mean radius of hardening $\beta^{\prime \prime}$ and $\beta^{\prime}$ precipitates (m)

$r_{\mathrm{c} 1} \quad$ Critical radius defining the hypothetical transition from shearing to bypassing of the clusters by dislocations in the expression for $F_{i}$ (m)

$r_{\mathrm{c} 2} \quad$ Critical radius defining the real transition from shearing to bypassing of the hardening $\beta^{\prime \prime}$ and $\beta^{\prime}$ precipitates by dislocations in the expression for $F_{j}(\mathrm{~m})$

$r_{i} \quad$ Radius of clusters within size class $i(\mathrm{~m})$

$r_{j} \quad$ Radius of hardening $\beta^{\prime \prime}$ and $\beta^{\prime}$ precipitates within size class $j(\mathrm{~m})$

$r_{r} \quad$ Radius of rod-shaped particles $(\mathrm{m})$

$R \quad$ Universal gas constant $(8.314 \mathrm{~J} / \mathrm{Kmol})$

$R_{p 0.2}$ Offset yield strength at $\varepsilon_{p}=0.002\left(\mathrm{~N} / \mathrm{m}^{2}\right.$ or $\mathrm{MPa})$

$t \quad$ Time (s)

$t_{1} \quad$ Storage time at RT before CD (s)

$t_{2} \quad$ Storage time at RT after CD (s)

$t_{3} \quad$ Holding time during AA (s)

$T \quad$ Temperature $\left(\mathrm{K}\right.$ or $\left.{ }^{\circ} \mathrm{C}\right)$

$T_{\mathrm{AA}} \quad$ Artificial aging temperature $\left(\mathrm{K}\right.$ or $\left.{ }^{\circ} \mathrm{C}\right)$

$T_{\mathrm{c}}^{*} \quad$ Temperature at which the nucleation rate of the clusters reaches its maximum value $\left(\mathrm{K}\right.$ or $\left.{ }^{\circ} \mathrm{C}\right)$

$T_{\mathrm{d}}^{*} \quad$ Temperature at which the nucleation rate of the $\beta^{\prime}$ particles at dislocations reaches its maximum value $\left(\mathrm{K}\right.$ or $\left.{ }^{\circ} \mathrm{C}\right)$

$U_{\mathrm{s}} \quad$ Average activation energy for solute diffusion in $\mathrm{SR}$ model $(\mathrm{J} / \mathrm{mol})$

$V_{\mathrm{m}} \quad$ Molar volume of clusters or hardening precipitates $\left(\mathrm{m}^{3} / \mathrm{mol}\right)$

$\alpha \quad$ Constant in expression for $\sigma_{d}$

$\beta \quad$ Equilibrium phase with assumed stoichiometric composition $\mathrm{Mg}_{2} \mathrm{Si}$

$\beta^{\prime \prime}, \beta^{\prime}$ Metastable phases with assumed stoichiometric composition $\mathrm{Mg}_{5} \mathrm{Si}_{3}$

$\beta_{1} \quad$ Constant in expressions for $F_{i}, F_{j}, \ell_{1}$ and $\ell_{2}$

$\varepsilon_{\mathrm{p}} \quad$ True plastic strain

$\gamma_{\mathrm{c}} \quad$ Cluster/matrix interfacial energy $\left(\mathrm{J} / \mathrm{m}^{2}\right)$

$\Omega_{\mathrm{c}} \quad$ Correction term for the reduced thermodynamic stability of clusters in TD model $(\mathrm{J} / \mathrm{mol})$

$\rho \quad$ matrix dislocation density $\left(\# / \mathrm{m}^{2}\right)$

$\rho_{\mathrm{c}} \quad$ Critical dislocation density which contributes to full overlap of the PFZs in NA and AA models $\left(\# / \mathrm{m}^{2}\right)$

$\rho_{\mathrm{s}} \quad$ Number density of statistically stored dislocations $\left(\left(\# / \mathrm{m}^{2}\right)\right.$

$\varphi \quad$ Aspect ratio of rod-shaped particles

$\sigma \quad$ True stress $\left(\mathrm{N} / \mathrm{m}^{2}\right.$ or $\left.\mathrm{MPa}\right)$

$\sigma_{\mathrm{d}} \quad$ Contribution from dislocations to the overall macroscopic yield stress $\left(\mathrm{N} / \mathrm{m}^{2}\right.$ or $\left.\mathrm{MPa}\right)$

$\sigma_{i} \quad$ intrinsic yield strength of pure aluminum $\left(\mathrm{N} / \mathrm{m}^{2}\right.$ or $\mathrm{MPa}$ )

$\sigma_{\mathrm{p}} \quad$ Contribution from all precipitates to the overall macroscopic yield stress ( $/ \mathrm{m}^{2}$ or $\left.\mathrm{MPa}\right)$

$\sigma_{\mathrm{p} 1} \quad$ Contribution from clusters to the overall macroscopic yield stress $\left(\mathrm{N} / \mathrm{m}^{2}\right.$ or $\left.\mathrm{MPa}\right)$

$\sigma_{\mathrm{p} 2} \quad$ Contribution from hardening $\beta^{\prime \prime}$ and $\beta^{\prime}$ precipitates to the overall macroscopic yield stress $\left(\mathrm{N} / \mathrm{m}^{2}\right.$ or $\left.\mathrm{MPa}\right)$ 
$\sigma_{\mathrm{p}}^{\mathrm{r}} \quad$ contribution from rod-shaped particles to the overall macroscopic yield stress $\left(\mathrm{N} / \mathrm{m}^{2}\right.$ or $\left.\mathrm{MPa}\right)$

$\sigma_{\mathrm{p}}^{\mathrm{s}} \quad$ contribution from monodispersive spherical particles to the overall macroscopic yield stress $\left(\mathrm{N} / \mathrm{m}^{2}\right.$ or $\left.\mathrm{MPa}\right)$

$\sigma_{\mathrm{ss}} \quad$ contribution from alloying elements in solid solution to the overall macroscopic yield stress $\left(\mathrm{N} / \mathrm{m}^{2}\right.$ or $\left.\mathrm{MPa}\right)$

$\sigma_{\mathrm{y}} \quad$ overall macroscopic yield stress

$\left(\mathrm{N} / \mathrm{m}^{2}\right.$ or $\left.\mathrm{MPa}\right)$

\section{APPENDIX B}

\section{EFFECT OF PARTICLE SHAPE ON OBSTACLE STRENGTH AND MATRIX YIELD STRESS}

The treatment given below applies to rod-shaped particles of uniform length $L_{\mathrm{r}}$ and radius $r_{\mathrm{r}}$, which are aligned in three independent $\langle 100\rangle$ directions, as shown schematically in Figure B1(a). Within the reference cube, it follows from Figure B1(b) that only one half of the particles with a fixed orientation in space, on the average, will intersect a given $\{111\}$ slip plane. Under such conditions, the relationship between the total

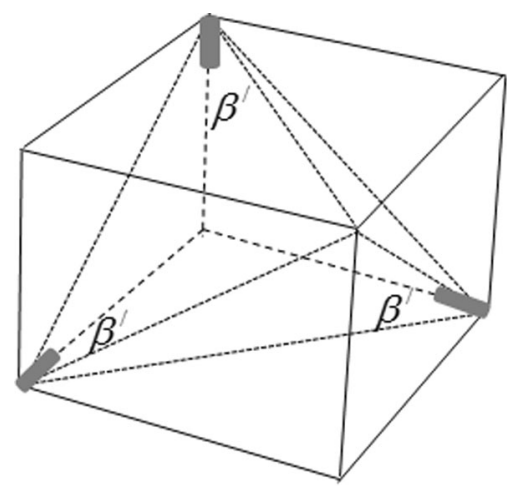

(a)

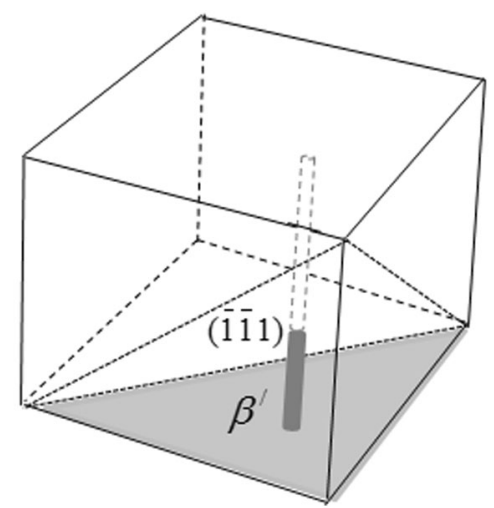

(b)

Fig. B1-Schematic outline of the model system used to evaluate the effect of particle shape on the $\sigma_{\mathrm{p}}$ strength contribution: $(a)$ assumed orientations of the rod-shaped $\beta^{\prime}$ particles with respect to the $\{111\}$ slip planes in the aluminum matrix, $(b)$ illustration of how one half of the rod-shaped $\beta^{\prime}$ particles with a fixed orientation in space intersects a given $\{111\}$ slip plane. number of particles per unit area of the slip planes $N_{a}^{r}$ and the total number of particles per unit volume $N_{\mathrm{v}}^{\mathrm{r}}$ becomes $^{[31,72]}$ :

$$
N_{\mathrm{a}}^{\mathrm{r}}=\frac{1}{\sqrt{3}} N_{\mathrm{v}}^{\mathrm{r}} L_{\mathrm{r}}
$$

Then, if $N_{v}^{r}$ is expressed in terms of the particle volume fraction $f_{r}$ and $L_{r}$ by the particle aspect ratio $\varphi$ (defined as $\varphi=L_{r} / 2 r_{r}$ ), then Eq. [B1] transforms to

$$
N_{a}^{r}=\left(\frac{4}{3 \sqrt{3} \pi}\right)^{1 / 3} \varphi^{2 / 3}\left(f_{r}\left(N_{v}^{r}\right)^{2}\right)^{1 / 3}
$$

For a monodispersive system of spherical particles, the corresponding relationship between $N_{\mathrm{a}}^{\mathrm{s}}, f_{s}$ and $N_{\mathrm{v}}^{\mathrm{s}}$ becomes

$$
N_{\mathrm{a}}^{\mathrm{s}}=\left(\frac{6 f_{\mathrm{s}}}{\pi}\left(N_{\mathrm{v}}^{\mathrm{s}}\right)^{2}\right)^{1 / 3}
$$

Furthermore, if one demands that the two particle distributions shall be mutually consistent and exhibit the same strength potential, both populations must have identical volume fractions $f_{\mathrm{r}}=f_{\mathrm{s}}$ and number densities $N_{\mathrm{v}}^{\mathrm{r}}=N_{\mathrm{v}}^{\mathrm{s}}$. This means that the distribution parameters $r_{\mathrm{r}}$ and $r_{\mathrm{s}}$ and $N_{\mathrm{a}}^{\mathrm{s}}$ and $N_{\mathrm{a}}^{\mathrm{r}}$ will be interrelated through the following equations:

$$
\begin{gathered}
r_{\mathrm{r}}=\left(\frac{2}{3 \varphi}\right)^{1 / 3} r_{\mathrm{s}}, \\
N_{\mathrm{a}}^{\mathrm{s}}=\left(\frac{9 \sqrt{3}}{2}\right)^{1 / 3}\left(\frac{1}{\varphi}\right)^{2 / 3} N_{\mathrm{a}}^{\mathrm{r}} .
\end{gathered}
$$

The next step is to invoke the general expressions relating the pertinent particle strength contributions $\sigma_{\mathrm{p}}^{\mathrm{r}}$ and $\sigma_{\mathrm{p}}^{\mathrm{s}}$ to the mean obstacle strength $\overline{F_{\mathrm{r}}}$ or $\overline{F_{\mathrm{s}}}$ and the mean effective particle spacing in the slip plane along the bending dislocation $\ell_{\mathrm{r}}$ or $\ell_{\mathrm{s}}$, respectively. ${ }^{[65]}$ Then, it follows from the treatment of Esmaeli et al. ${ }^{[31]}$ that the obstacle strength of both rod-shaped and spherical particles during shearing can be captured by means of single parameter $m$, which has a defined value, depending on their impeding effect on the dislocation motion. In the present case, where only the strength ratio $\sigma_{\mathrm{p}}^{\mathrm{r}} / \sigma_{\mathrm{p}}^{\mathrm{s}}$ is sought, the following simple power law solution exists between this ratio and the parameters $m$ and $\varphi$ when $m>0$ :

$$
\frac{\sigma_{\mathrm{p}}^{\mathrm{r}}}{\sigma_{\mathrm{p}}^{\mathrm{s}}}=\frac{\overline{F_{\mathrm{r}}}}{\overline{F_{\mathrm{s}}}} \frac{\ell_{\mathrm{s}}}{\ell_{\mathrm{r}}}=3^{\frac{-5-6 m}{12}} 2^{\frac{3 m+1}{6}} \varphi^{\frac{2-3 m}{6}},
$$

In Eq. [B6], $m=1$ refers to shearable particles with an obstacle strength analogous to that assumed in NaMo-Version 1. 


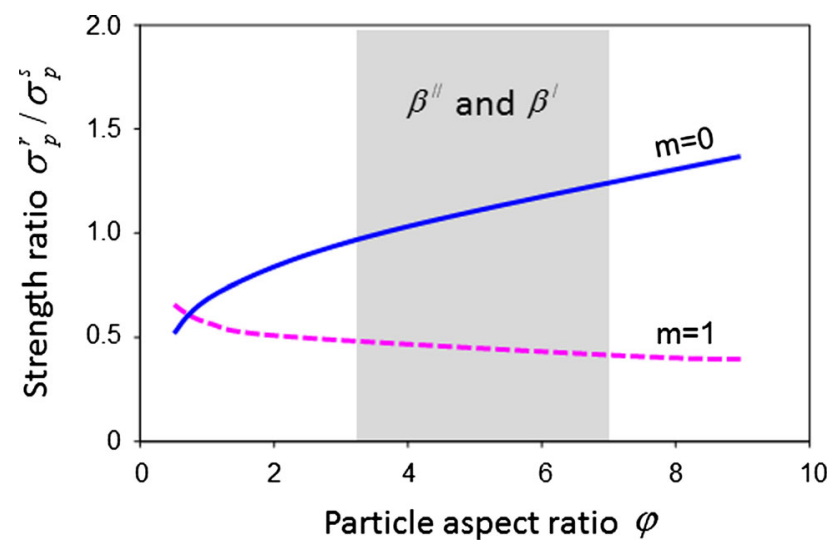

Fig. B2 - Graphical representations of Eqs. [B6] and [B7] showing how the $\sigma_{\mathrm{p}}^{\mathrm{r}} / \sigma_{\mathrm{p}}^{\mathrm{s}}$ ratio varies with the particle aspect ratio $\varphi$ and the dislocation locking mechanism (characterized by $m=0$ and $m=1$, respectively). The shaded area in the diagram indicates the typical range in the aspect ratio for the hardening $\beta^{\prime \prime}$ and $\beta^{\prime}$ precipitates.

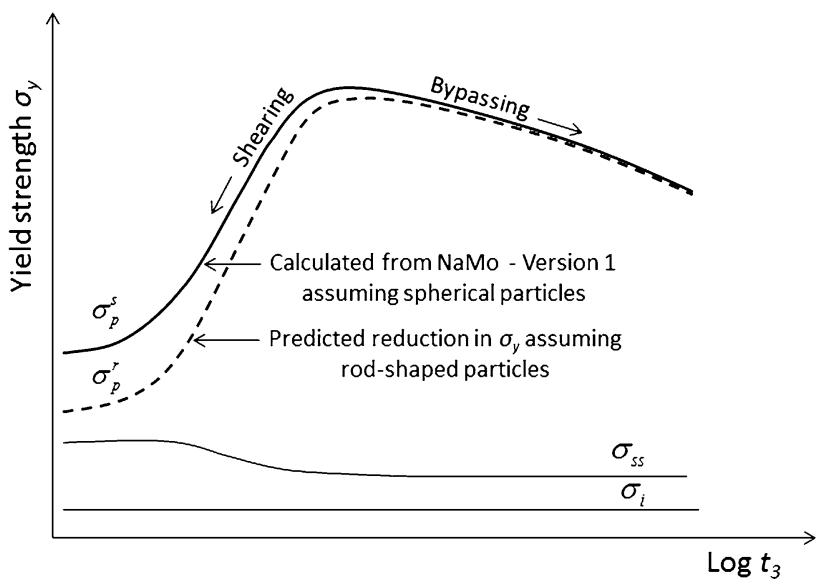

Fig. B3-Semi-schematic plots showing how the particle aspect ratio affects the RT yield strength following artificial aging. The solid curves refer to predictions based on NaMo-Version 1 assuming spherical particles. The broken curve indicates the shift in the yield stress if the particles instead are assumed to be rod-shaped with an aspect ratio close to 5 .

If the same analysis is done for $m=0$, the corresponding solution for non-shearable particles of the Orowan type becomes

$$
\frac{\sigma_{\mathrm{p}}^{\mathrm{r}}}{\sigma_{\mathrm{p}}^{\mathrm{s}}}=3^{-\frac{1}{6}} 2^{-\frac{1}{3}} \varphi^{\frac{1}{3}}
$$

It is evident from the graphical representations of Eqs. [B6] and [B7] in Figure B2 that the $\sigma_{\mathrm{p}}^{\mathrm{r}} / \sigma_{\mathrm{p}}^{\mathrm{s}}$ strength ratio is only a weak function of the particle aspect ratio $\varphi$ within the range being reported for hardening $\beta^{\prime \prime}$ and $\beta^{\prime}$ precipitates in Al-Mg-Si alloys. ${ }^{[17]}$ Still, there is a significant difference in the absolute $\sigma_{\mathrm{p}}^{\mathrm{r}} / \sigma_{\mathrm{p}}^{\mathrm{s}}$ ratio between shearable and non-shearable particles, which suggests that the shape effect is mainly related to the actual dislocation locking mechanism.

To what extent a change in the dislocation locking mechanism will affect the resulting RT yield stress $\sigma_{\mathrm{y}}$ following artificial aging is difficult to quantify, but the shape effect will clearly be small for non-shearable particles, which are characterized by a $\sigma_{\mathrm{p}}^{\mathrm{r}} / \sigma_{\mathrm{p}}^{\mathrm{s}}$ ratio close to unity. These are the dominant type controlling the form of the hardening curve to the right of the peak, as shown schematically in Figure B3. In contract, the difference in matrix yield strength between rod-shaped and spherical particles becomes much larger if they are shearable, which is typical for precipitates in under-aged Al-Mg-Si alloys. ${ }^{[17]}$ Referring again to Figure B3, a $\sigma_{\mathrm{p}}^{\mathrm{r}} /$ $\sigma_{\mathrm{p}}^{\mathrm{s}}$ ratio close to 0.45 means that the front part of the hardening curve for rod-shaped particles will drop significantly below the corresponding curve calculated from NaMo-Version 1 assuming spherical particles. This curve-shift visualizes the magnitude of the particle shape effect compared to other contributions under otherwise identical conditions.

In practice, however, this difference in the obstacle strength between rod-shaped and spherical particles can easily be accounted for if the yield strength model is calibrated before use against experimental data, as done in NaMo-Version 1 and 2. As a matter of fact, this is a standard operating procedure in all industrial process modeling. Hence, the contribution from particle shape is deemed to be a second order effect in the context of the modified yield strength model being developed. Therefore, although physically based yield strength models capable of handling rod-shaped particles already exist, ${ }^{[72,73]}$ they will not be implemented in NaMo-Version 2 because of the additional complications that such a refinement creates when it comes to modifying the existing nanostructure models to allow for the particle shape effect. However, the work on extending their applicability has now started, ${ }^{[74,75]}$ which, in turn, may clear the way for a full treatment of the non-spherical particle case as well within the framework of the Kampmann-Wagner formalism if this is deemed to be necessary in the future.

\section{REFERENCES}

1. H.R. Shercliff and M.F. Ashby: Acta Metall., 1990, vol. 38, pp. 1789-02.

2. L.M. Cheng, W.J. Poole, J.D. Embury, and D.J. Lloyd: Metall. Mater. Trans. A, 2003, vol. 34A, pp. 2473-81.

3. D.H. Bratland, Ø. Grong, H.R. Shercliff, O.R. Myhr, and S. Tjøtta: Acta Mater., 1997, vol. 45 (1997), pp. 1-22.

4. C.D. Marioara, H. Nordmark, S.J. Andersen, and R. Holmestad: J. Mater. Sci., 2006, vol. 41, pp. 471-78.

5. K. Teichmann, C.D. Marioara, K.O. Pedersen, and K. Marthinsen: Mater. Sci. Eng. A, 2013, vol. 565, pp. 228-35.

6. R. Vissers, M.A. van Huis, J. Jansen, H.W. Zandbergen, C.D. Marioara, and S.J. Andersen: Acta Mater., 2007, vol. 55, pp. 3815-23.

7. M. Torsæter, H.S. Hasting, W. Lefebvre, C.D. Marioara, J.C. Walmsley, S.J. Andersen, and R. Holmestad: J. Appl. Phys., 2010, vol. 108 , pp. 073527-1-9.

8. S.J. Andersen, C.D. Marioara, R. Vissers, A. Frøseth, and H.W. Zandbergen: Mater. Sci. Eng. A, 2007, vol. 444, pp. 157-69.

9. R. Vissers, C.D. Marioara, S.J. Andersen, and R. Holmestad: Aluminium Alloys, 2008, vol. 2, pp. 1263-69.

10. P.H. Ninive, A. Strandlie, S. Gulbrandsen-Dahl, W. Lefebvre, C.D. Marioara, S.J. Andersen, J. Friis, R. Holmestad, and O.M. Løvvik: Acta Mater., 2014, vol. 69, pp. 126-34. 
11. D.W. Pashley, M.H. Jacobs, and J.T. Vietz: Phil. Mag., 1967, vol. 16, pp. 51-76.

12. G. Edwards, K. Stiller, G. Dunlop, and M. Couper: Acta Mater., 1998, vol. 46, pp. 3893-04.

13. L. Zhen, W.D. Fei, S.B. Kang, and H.W. Kim: J. Mater. Sci., 1997, vol. 32, pp. 1895-02.

14. M. Murayama, K. Hono, M. Saga, and M. Kikuchi: Mater. Sci. Eng. A, 1998, vol. 250, pp. 127-32.

15. I. Dutta and S.M. Allen: J. Mater. Sci. Lett., 1991, vol. 10, pp. $323-26$.

16. W.F. Miao and D.E. Laughlin: Scripta Mater., 1999, vol. 40, pp. 873-78.

17. C.D. Marioara, S.J. Andersen, J. Jansen, and H.W. Zandbergen: Acta Mater., 2001, vol. 49, pp. 321-28.

18. S. Pogatscher, H. Antrekowitsch, H. Leitner, T. Ebner, and P.J. Uggowitzer: Acta Mater., 2011, vol. 59, pp. 3352-63.

19. S. Pogatscher, H. Antrekowitsch, and P.J. Uggowitzer: Acta Mater., 2012, vol. 60, pp. 5545-54.

20. O.R. Myhr and Ø. Grong: Acta Mater., 2000, vol. 48, pp. 1605-15.

21. O.R. Myhr, Ø. Grong, and S.J. Andersen: Acta Mater., 2001, vol. 49 , pp. $65-75$.

22. O.R. Myhr, Ø. Grong, and K.O. Pedersen: Metall. Mater. Trans. $A$, 2010, vol. 41A, pp. 2276-89.

23. J.K. Holmen, T. Børvik, O.R. Myhr, H.G. Fjær, and O.S. Hopperstad: Int. J. Impact Eng., 2015, vol. 84, pp. 96-107.

24. O. Engler, C. Schäfer, and O.R. Myhr: Mater. Sci. Eng. A, 2015 , vol. 639 , pp. $65-74$.

25. N.H. Hoang, O.S. Hopperstad, O.R. Myhr, C. Marioara, and M. Langseth: Thin Walled Struct., 2015, vol. 92, pp. 93-103.

26. C. Dørum, O.G. Lademo, O.R. Myhr, T. Berstad, and O.S. Hopperstad: Comput. Struct., 2010, vol. 88, pp. 519-28.

27. O.R. Myhr, Ø. Grong, O.G. Lademo, and T. Tryland: Weld. J., 2009, vol. 88, pp. 42-45.

28. O.R. Myhr, Ø. Grong, H.G. Fjær, and C.D. Mariorara: Acta Mater., 2004, vol. 52, pp. 4997-08.

29. O.R. Myhr and Ø. Grong: ASM Handbook, Welding Fundamentals and Processes, ASM, vol. 6A, 2011, pp. 797-18.

30. J. Johnsen, J.K. Holmen, O.R. Myhr, O.S. Hopperstad, and T. Børvik: Comput. Mater. Sci., 2013, vol. 79, pp. 724-35.

31. S. Esmaeili, D.J. Lloyd, and W.J. Poole: Acta Mater., 2003, vol. 51 , pp. $3467-81$.

32. S. Esmaeili, X. Wang, D.J. Lloyd, and W.J. Poole: Metall. Mater. Trans. A, 2003, vol. 34A, pp. 751-63.

33. X. Wang, W.J. Poole, S. Esmaeili, D.J. Lloyd, and J.D. Embury: Metall. Mater. Trans. A, 2003, vol. 34A, pp. 2913-23.

34. E. Nes: Acta Mater., 1995, vol. 43, pp. 2189-07.

35. J.A. Sæter, B. Forbord, H.E. Vatne, and E. Nes: Proc. 6th International Conference on Aluminium Alloys, Toyohashi, Japan, 1998, pp. 113-26.

36. E. Nes and K. Marthinsen: Mater. Sci. Eng., 2002, vol. A322, pp. 176-93.

37. M. Murayama and K. Hono: Acta Mater., 1999, vol. 47, pp. $1537-48$.

38. Y. Takaki, Y. Aruga, M. Kozuka, and T. Sato: Proc. 14th International Conference on Aluminium Alloys, Materials Science Forum vol. 794-796, 2014, pp. 1026-31.

39. M.J. Starink, N. Gao, L. Davin, J. Yan, and A. Cerezo: Phil. Mag., 2005, vol. 85, pp. 1395-17.

40. P. Lang, P. Mohn, A. Falahati, and E. Kozeschnik: Proc. 13th International Conference on Aluminium Alloys, Wiley \& Sons, Inc., 2012, pp. 273-77.

41. Z. Liang: Doctoral Thesis, Institute of Applied Materials, Berlin, 2012/2013.

42. A. Bahrami: Doctoral Thesis, Delft University of Technology, Department of Material Science and Engineering, Delft, 2010.

43. A.K. Gupta and D.J. Lloyd: Metall. Mater. Trans. A, 1999, vol. 13A, pp. 879-84.

44. R. Wagner and R. Kampmann: Material Science and Technology-A Comprehensive Treatment, vol. 5, VCH, 1991, pp. 213-03.
45. R. Kampmann, H. Eckerlebe, and R. Wagner: Mat. Res. Soc. Symp. Proc., MRS, 1987, vol. 57, pp. 525-42.

46. K.C. Russel: Phase Transformations, Metals Park, OH, ASM, 1970, pp. 219-68.

47. C. Ravi and C. Wolverton: Acta Mater., 2004, vol. 52, pp. 4213-27.

48. K. Teichmann, C.D. Marioara, S.J. Andersen, and K. Martinsen: Metall. Mater. Trans. A, 2012, vol. 43A, pp. 4006-14.

49. K. Teichmann, C.D. Marioara, S.J. Andersen, and K. Martinsen: Mater. Charact., 2013, vol. 75, pp. 1-7.

50. J.D. Embury and R.B. Nicholson: Acta Metall., 1965, vol. 13, pp. 403-17.

51. G.W. Lorimer and R.B. Nicholson: Acta Metall., 1966, vol. 14, pp. $1009-13$.

52. A. Deschamps and Y. Brechet: Acta Mater., 1999, vol. 47, pp. 293-05.

53. D.A. Porter and K.E Easterling: Phase Transformations in Metals and Alloys, Wokingham (England), Van Nostrand Reinhold Co. Ltd., 1981.

54. W.J. Poole, H.R. Shercliff, and T. Castillo: Mater. Sci. Technol., 1997, vol. 13, pp. 897-04.

55. E.P. Karadeniz, P. Lang, P. Warczok, A. Falahati, W. Jun, and E. Kozeschnik: CALPHAD, Computer Coupling of Phase Diagrams and Thermochemistry, Elsevier, 2013, vol. 43, pp. 94-104.

56. T. Furu, Ø. Ryen, and O.R. Myhr: Proc. 11th Int. Conf. on Aluminium Alloys, Aachen, Germany, Wiley-VCH, 2008, pp. 162633.

57. U.F. Kocks: Phil. Mag., 1966, vol. 13, pp. 541-66.

58. F.J. Humphreys and M. Hatherly: Recrystallization and Related Annealing Phenomena, 2nd ed., Oxford (UK), Elsevier Ltd., 2004, pp. 469-78.

59. G.E. Dieter: Mechanical Metallurgy, 2nd ed., McGraw-Hill Book Company, New York, 1976, pp. 190-99.

60. I. Westermann, O.S. Hopperstad, K. Martinsen, and B. Holmedal: J. Mater. Sci., 2010, vol. 45, pp. 5323-31.

61. A.L. Dons, E.K. Jensen, Y. Langsrud, E. Trømborg, and S. Brusethaug: Metall. Mater. Trans. A, 1999, vol. 30A, pp. 213546.

62. A.L. Dons: J. Light Met., 2001, vol. 1, pp. 133-48.

63. J. Friedel: Dislocations, Pergamon Press, Oxford, 1964

64. F.R.N. Nabarro: Theory of Crystal Dislocations, Oxford University Press, Oxford (UK), 1967.

65. B. Reppich: Material Science and Technology-A Comprehensive Treatment, vol. 6, VCH, 1993, pp. 311-57.

66. Y. Aruga, M. Kozuka, Y. Takaki, and T. Sato: Proc. 14th International Conference on Aluminium Alloys, Materials Science Forum vol. 794-796, 2014, pp. 897-02.

67. M.F. Ashby and D.R.H. Jones: Engineering Materials-An Introduction to their Properties and Applications, Pergamon Press, Oxford (England), 1980.

68. J.E. Hatch: Aluminium-Properties and Physical Metallurgy, American Society for Metals, Metals Park, OH, 1984

69. J. Gerold: Dislocations in Solids, vol. 4, North Holland Publ. Co., Amsterdam, 1979.

70. J.W. Martin, R.D. Doherty, and B. Cantor: Stability of Microstructure in Metallic Systems, Cambridge University Press, 1997.

71. M. Khadyko, O.R. Myhr, S. Dumoulin, and O.S. Hopperstad: Modelling and Simulation in Materials Science and Engineering, in press.

72. D. Bardel, M. Perez, D. Nelias, A. Deschamps, C.R. Hutchinson, D. Maisonnette, T. Chaise, J. Garnier, and F. Bourlier: Acta Mater., 2014, vol. 62, pp. 129-40.

73. A. Bahrami, A. Miroux, and J. Sietsma: Metall. Mater. Trans. A, 2012, vol. 43A, pp. 4445-53.

74. B. Holmedal, E. Osmundsen, and Q. Du: Metall. Mater. Trans. A, in press.

75. Q. Du, B. Holmedal, J. Friis, and C. Marioara: Metall. Mater. Trans. $A$, in press. 